\title{
DIDÁCTICA DE LA GEOGRAFÍA Y SU APLICACIÓN A LA ENSEÑANZA DE LA GEOGRAFÍA EN EL TERCER CICLO Y LA ENSEÑANZA DIVERSIFICADA DE COSTA RICA
}

\author{
Gilbert Vargas Ulate \\ Docente de la Escuela de Geografía de la \\ Universidad de Costa Rica \\ San José, Costa Rica
}

Recibido 26-V-2008 • Aceptado 25-V-2009 • Corregido 8-VI-2009

\begin{abstract}
Resumen: La didáctica de la geografía en las escuelas y colegios debe dejar los elementos tradicionales $y$ obsoletos que constituyen la base del saber geográfico en la actualidad. Al respecto, la enseñanza de esa disciplina se encuentra en una situación deficiente y limitada en Costa Rica por dos razones: una formación geográfica del profesorado limitada, parcial y tradicional, y la ausencia de reflexión sobre la didáctica de la disciplina. En el artículo se sostiene la tesis de que los estudiantes deben adquirir nociones y habilidades que se interrelacionen, pero para que ello ocurra es necesario estructurar la enseñanza de la Geografía de manera gradual y significativa para el estudiantado.
\end{abstract}

Palabras clave: Geografía, enseñanza de la Geografía, Didáctica de la Geografía, enseñanza de los Estudios Sociales en Costa Rica.

\section{Introducción}

En el sistema educativo costarricense, por razones de comodidad administrativa, la enseñanza de la Geografía se asocia, tradicionalmente, a la de la Historia. Aunque esto no quiere decir que estas dos disciplinas se articulen e interrelacionen adecuadamente en los programas de Estudios Sociales de escuelas y colegios. La enseñanza de la Geografía genera dudas porque se enseña mal, los educadores tienen grandes limitaciones epistemológicas, es percibida por los estudiantes como poco útil y aburrida, además es dominada por la Historia. Esta situación genera un rezago de la Geografía como asignatura frente a la Geografía como disciplina científica. Pero, ¿dónde y cuándo nace este rezago? Varios argumentos podrían explicarlo:

Primero, la enseñanza de la Geografía se estanca a partir de 1954, cuando se deja de impartir como disciplina individual en los programas de estudio de escuelas y colegios y pasa a formar parte de los Estudios Sociales. 


\begin{abstract}
The Didactics of Geography in the schools must leave traditional and obsolete elements that constitute the basis of the geographic knowledge at the present time. On the matter, the education of that discipline is in a deficient and limited situation in Costa Rica for two reasons: geographic formation of the teaching staff is limited, partial and traditional, and the absence of reflection on the Didactics of the discipline. In the article, it is maintained the thesis that the students must acquire slight knowledge and abilities that interrelate, but so that it happens, it is necessary to structure the education of Geography gradually and significantly for the students.
\end{abstract}

Key words: Geography, teaching of Geography, Didactics of Geography, education of the Social Studies in Costa Rica.
Segundo, la enseñanza de la Geografía se enfatiza en el estudio regional descriptivo, lo que trae como consecuencia muchos problemas en su enseñanza, entre ellos se acentúa la enseñanza descriptiva, se desplaza al educando de su entorno, se consolida la memorización, el aprendizaje se convierte en una actividad reproductiva, se privilegia el conocimiento en lugares y conceptos muchas veces mal empleados, se convierte la enseñanza en un proceso mecánico de transmitir contenidos, la clase es una actividad excesivamente rutinaria donde predomina el dictado y no la explicación de procesos y fenómenos, el uso de libros de texto se constituye en la única fuente de conocimiento de los educadores y educandos, la evaluación es una manifestación concreta de la reproducción de los contenidos. En resumen, la enseñanza de la geografía en escuelas y colegios del país es memorista, repetitiva, descriptiva y desactualizada.

Ante este tipo de enseñanza de la disciplina, el cambio debe comenzar por una enseñanza más aplicada a la realidad, partir de un conocimiento del funcionamiento de los procesos y fenómenos geográficos y convertirse en más activa y práctica por parte del estudiante. Para ello es necesario facilitar las herramientas intelectuales que permitan a los educadores obtener y aplicar correctamente los conceptos, de manera que sirvan para explicar reflexiva y críticamente el paisaje geográfico.

Para que el estudiante logre un aprendizaje adecuado de la disciplina, es necesario un contacto directo con el entorno geográfico (paisaje geográfico) mediante el análisis de los fenómenos geográficos por medio de imágenes, mapas, gráficos.

En este estudio se pretende, en primera instancia, analizar la situación de la enseñanza de la Geografía en el tercer ciclo y la enseñanza diversificada de Costa Rica y luego plantear algunas estrategias didácticas para hacer de la Geografía una disciplina analítica y motivadora. 


\section{La Geografía como disciplina científica}

Desde tiempos de la Grecia clásica se hicieron descripciones geográficas como las de Heródoto y los aportes de la geografía matemática al conocimiento de la cartografía -utilizada en una forma práctica por los romanos para conformar su gran imperio-. Posteriormente, los árabes y los chinos retomaron el conocimiento griego e hicieron importantes avances en la cartografía y la representación de la Tierra, con los cuales favorecieron los grandes descubrimientos de la llamada geografía de los viajeros. Pese a los logros de las civilizaciones antiguas, no fue sino hasta en el siglo XIX cuando la Geografía se constituyó como disciplina científica gracias a las exploraciones y aportes de Alexander von Humboldt.

Humboldt consideraba que la esfera terrestre se dividía en dos partes: la naturaleza inorgánica y la naturaleza orgánica. La primera comprende la forma y densidad de la Tierra, su calor interno, su actividad electromagnética, la constitución mineralógica de la corteza, la influencia de su interior sobre su superficie -realizada dinámicamente por su ruptura y químicamente por fenómenos que forman y transforman las rocas-, por las aguas y continentes que interactúan y, por último, la envoltura gaseosa que envuelve al globo o, en otros términos, la atmósfera. El dominio orgánico comprende la geografía de las plantas y animales y las acciones de la especie humana, estableciéndose relaciones reciprocas entre la sociedad y la naturaleza (Vargas, 2007).

Por la subdivisión de la Geografía en múltiples disciplinas como la climatología, geomorfología, biogeografía, hidrología y edafología (Vargas, 2007), la geografía física creada por Humboldt y su análisis integrado del medio natural no fue considerado más a finales del siglo XIX. Por esta división, durante las primeras tres décadas del siglo XX, la Geografía siguió un análisis regional descriptivo y poco analítico el cual, al encerrarse en sí mismo, se aisló por completo de las otras ciencias de la naturaleza y la tierra.

A partir de 1930, la antigua Unión Soviética se enfrenta a la necesidad de conocer un vasto territorio, muy heterogéneo y de grandes recursos. Para el conocimiento de las riquezas naturales y sociales, con los cuales planificar su desarrollo, los geógrafos soviéticos logran crear una geografía analítica y representativa. Analítica, porque considera el espacio geográfico como un sistema donde interactúan los fenómenos naturales y sociales, representando una unidad dialéctica en continuo movimiento y desarrollo. Representativa, porque se realiza una cartografía (mapas) donde se establecen las relaciones sociedad-naturaleza.

Este análisis integrador del espacio geográfico, iniciado por los soviéticos, continúa en la década de los cuarenta, en la antigua República Democrática de Alemania, por medio de la geografía del paisaje; posteriormente, a partir de 1950, se prosigue en Francia y en los Estados Unidos (Vargas, 2007).

La Geografía actual parte de la idea de que existe una representación y apropiación de la naturaleza por la sociedad. La representación, por medio del uso del mapa, se constituye en el elemento fundamental del análisis geográfico. La apropiación, por la interacción que el ser humano realiza con el ambiente.

\section{La Geografía en Costa Rica: representantes y enfoques}

En Costa Rica, la primera obra sobre Geografía fue la del Bachiller Osejo, llamada Lecciones de geografía en forma de catecismo. La forma de catecismo se debe a que los temas de geografía se planteaban en forma de preguntas concretas, a las que se daba una respuesta (Osejo, 1833). En 1885, con la reforma educativa de Mauro Fernández, la educación adquirió peso y significación relevante. De esta manera, desde la creación 
del Colegio San Luis Gonzaga, el Liceo de Costa Rica, el Colegio de Señoritas y el Instituto de Alajuela, a finales del siglo XIX y hasta 1953, la Geografía se constituyó en una asignatura independiente en los programas de enseñanza, destacando los trabajos del profesor Henri Pittier y Miguel Obregón.

Llama la atención el alto nivel y la importancia dada en los libros de Geografía a textos de importantes geógrafos como Eliseo de Reclus (Obregón, 1932). Carmen Lyra, en la presentación de la Geografía de Miguel Obregón destacó que:

.. ya la Geografía no es más la asignatura fastidiosa con su rosario de nombres de ciudades, de ríos, de montañas, ya no se trata tan solo de aprender de memoria la extensión territorial de la China, ni el número de habitantes de Guatemala. No, no, es otra cosa, es la vida nuestra Tierra con sus pueblos diferentes que le arañan la corteza que se presenta rebelde en las montañas y se tiende dócil en las llanuras y con la continua inquietud de sus mares y sus ríos, de sus vientos y de sus lluvias (p. 5).

Otros textos de geografía que destacan en el contexto costarricense son los Jorge León (1942) y Tulia Quirós (1944).

Con la creación de la Universidad de Costa Rica en 1942, la Geografía se estableció al lado de la Historia como apéndice de esta, pues se le otorgó mayor importancia administrativa y docente a la Historia; además tuvo un marcado énfasis en la geografía regional tradicional (Monge, 1943). Esta relación de la geografía y la historia a nivel universitario tuvo peso en la reforma educativa implementada por Uladislao Gámez, durante el gobierno de José Figueres Ferrer, es así como a partir de 1954, la enseñanza de la Geografía en escuelas y colegios dejó de impartirse en forma independiente para formar parte del nuevo programa de Estudios Sociales, que integraba la Geografía, la Historia y la Cívica.

En 1963, llegó al Departamento de Historia y Geografía de la Facultad de Ciencias y Letras una misión de la Universidad de Kansas, encabezada por los geógrafos John Augellie y Pierre Stouse.
Ambos propusieron al entonces director, Carlos Meléndez, la creación de nuevos e innovadores programas de estudio en la disciplina y la creación del Departamento de Geografía. No obstante, la propuesta nunca se llevó a la práctica.

La Geografía moderna, como ciencia que estudia la organización y la diferenciación del espacio, nació tardíamente en Costa Rica. En 1973, se creó la Escuela de Ciencias Geográficas de la Universidad Nacional y en 1975, a los dos años se constituyó el Departamento de Geografía en la Universidad de Costa Rica. Es a partir de este momento que se inició la enseñanza de la Geografía como ciencia y aparecieron las dos primeras publicaciones de la Geografía moderna en Costa Rica: la de Eusebio Flores (1973) y la de Carolyn Hall (1984).

Las escuelas de Geografía se han dedicado a la formación de geógrafos profesionales, pero lamentablemente se han descuidado los cursos de Geografía que forman parte del programa de formación de profesores de Estudios Sociales y no se han establecido relaciones estrechas con las Facultades de Educación, responsables de los cursos de Didáctica.

\section{La didáctica y la didáctica de la Geografía}

La Didáctica es la disciplina de carácter práctico y normativo que tiene por objeto específico la técnica de la enseñanza; esto es, la técnica de dirigir y orientar eficazmente al alumnado en su aprendizaje, definida en relación con su contenido. La didáctica establece el conjunto sistemático de principios, normas, recursos y procedimientos específicos que todo profesor debe conocer y saber aplicar para orientar con seguridad a sus los alumnos en el aprendizaje de las materias de los programas, teniendo en vista los objetivos educativos (Polanco, 1976).

El objetivo principal de la Didáctica es transmitir de una manera sencilla, correcta 
y motivadora los contenidos de una determinada materia, en este caso la Geografía, siempre y cuando se considere la realidad de la clase y de los alumnos. No existe una mejor técnica de enseñanza, en términos absolutos y determinable a priori; pero, en circunstancias reales, siempre es posible determinar cuál es, en cada caso, la técnica de enseñanza más factible y aconsejable, ello exige comprender y discernir todos los datos de la situación real e inmediata sobre la que se va a actuar (Polanco, 1976).

La Didáctica está constituida por tres elementos fundamentales: el saber disciplinar, el alumno y el profesor. En la
Figura 1 cada uno de estos elementos ocupa un vértice del triángulo. La Didáctica analiza esos elementos por separado: el saber o contenido de la disciplina, lo que el alumno es y sabe, y la forma de enseñar del docente por medio de los programas, textos y la formación profesional; así también analiza las relaciones entre los vértices por medio de tres procesos. El primero es el proceso de enseñanza que establece la relación entre el docente y el saber disciplinar; el segundo es el proceso de aprendizaje que se establece entre el alumno y saber disciplinar y el tercero es el proceso de comunicación entre el docente y el alumno (Le Roux, 2003).

Figura 1

El triángulo didáctico según Le Roux

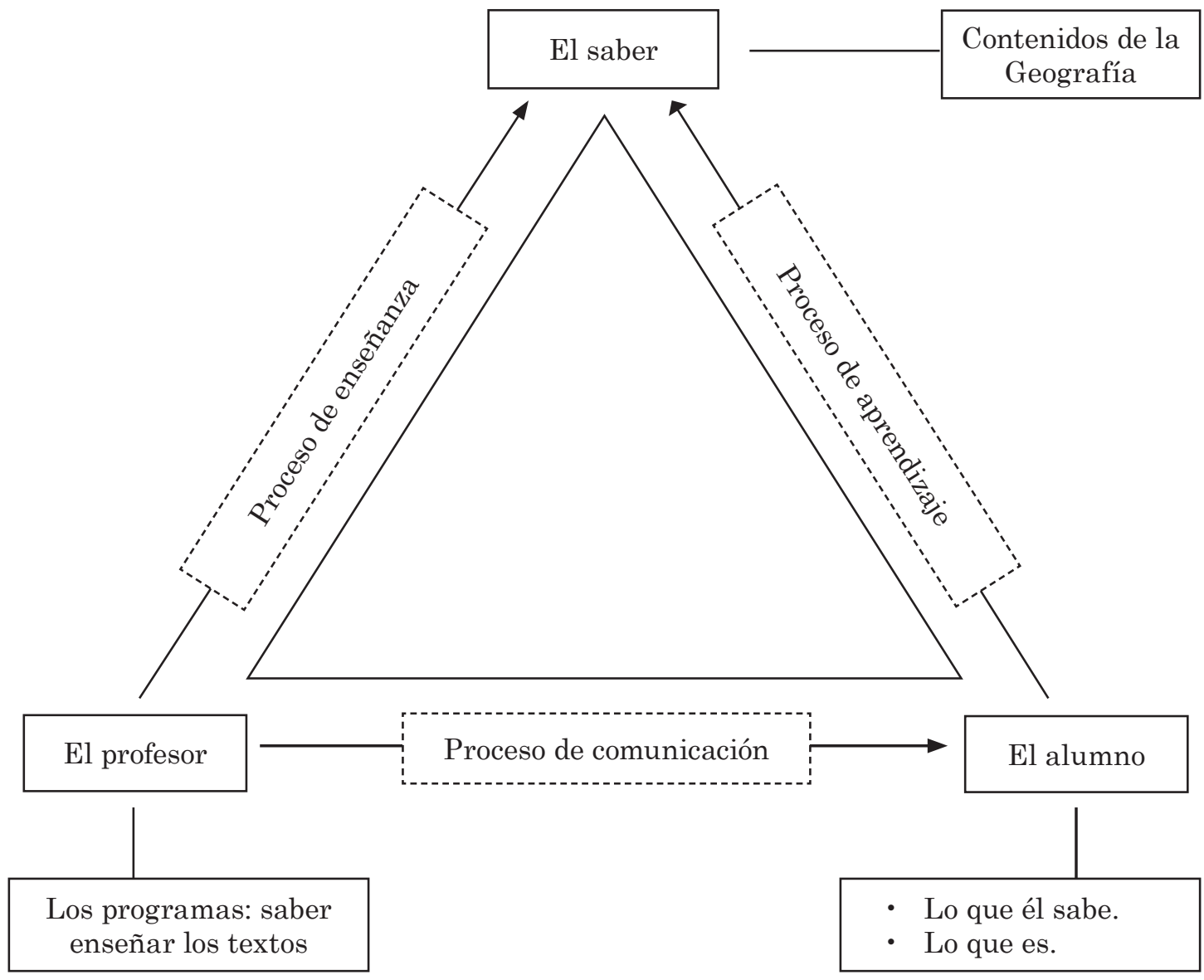

Fuente: Le Roux, 2003. 
La enseñanza de la Geografía supone la existencia de una Didáctica de la Geografía; sin embargo, en el nivel universitario cada geógrafo logra progresos en sus investigaciones y en el conocimiento de la Geografía, pero al impartir cursos, por lo general, no se aplican procedimientos para transmitir eficientemente el saber geográfico a los estudiantes. Los geógrafos en las universidades son más investigadores que profesores, al no considerar el conocimiento, los conceptos y los métodos de enseñanza en función de las capacidades de los estudiantes.

En muchas ocasiones se señala que la enseñanza de la Geografía en las escuelas y colegios es memorista, teórica, repetitiva de conceptos, pasiva, poco motivadora y se atribuye la responsabilidad de esas deficiencias a las maestras de primaria y a los profesores de secundaria por impartir deficientemente los contenidos de Geografía dentro del programa de Estudios; sin embargo, cuando estos docentes pasaron por las aulas universitarias no recibieron la formación necesaria sobre ¿cómo transmitir los conceptos geográficos?, ¿qué métodos utilizar?, ¿qué prácticas realizar?, por lo que únicamente dominan la simple transmisión de conocimientos en las geografías regionales que aprobaron.

La Geografía universitaria se aleja de la enseñanza de la disciplina, siguiendo una orientación científica y desarrollando investigaciones cada vez más precisas y detalladas. La consecuencia de esta situación es la dualidad "saber universitario"-"saber escolar", llamadas también "Geografía sabia" y "Geografía de la enseñanza". Distanciamiento que se ahonda cada vez más provocando relaciones y una comunicación más difícil entre una y otra (Desplanques, 1991; Pinchemel, 1997).

Pese al distanciamiento mencionado entre la Geografía sabia y la Didáctica de la Geografía, existen estudios sobre la enseñanza de la Geografía. Entre ellos destacan: Perpectives in geographical education (Bale, Graves y Walford, 1985), New directions in geography teaching (Walford, 1978), Games in geography (Walford, 1979), New movements in the study and teaching of geography (Graves, 1993), Les tendances nouvelles dans l'enseignement de la geographie (Henriet, 1977) y La recherche en didactique de la géographie (Daudel, 1986). En estas obras se analiza una variedad de temas que comprenden objetivos, conceptos, programas y técnicas de enseñanza, y todas se articulan por medio de dos argumentaciones principales: el valor educativo de la buena aplicación de los conceptos y la necesidad de implementar nuevos métodos de enseñanza. Por ello, es nuestro interés, analizar conceptualmente la Didáctica de la Geografía y su aplicación a la enseñanza de la Geografía en los colegios de Costa Rica.

La Geografía tiene por objeto el estudio de la organización y la diferenciación del espacio. Como todo espacio, el del geógrafo está construido por la interacción de los elementos naturales o espacio natural y por la acción de los seres humanos o espacio social o cultural (Brunet, 1989). Rougerie (1986) considera que la Geografía es el estudio de los paisajes que se definen como la porción visible del espacio y tiene por objetivo localizar, describir, explicar y comparar todos los elementos físicos y culturales que componen integralmente el paisaje. El análisis del espacio geográfico requiere del uso y soporte de mapas, que son el rasgo distintivo de la Geografía.

La Geografía no se define en términos de sus contenidos propios, porque no los tiene, debido a que es una ciencia de síntesis que toma de los contenidos de otras ciencias, pero los hace suyos al aplicar la cartografía como su propio método (Vargas, 2006). Por esta razón, la Geografía no se define por sus contenidos, sino por su método; es decir, los contenidos o problemas que asume la Geografía de otras disciplinas se representan en forma 
cartográfica y ese es el punto de partida del análisis geográfico.

La Didáctica de la Geografía toma en cuenta las condiciones del aprendizaje para hacer comprensibles los conceptos y los métodos geográficos. La enseñanza de la Geografía en las escuelas y colegios es elemental, pero no se debe interpretar como una enseñanza parcial y simplista; Por el contrario, elemental, en este caso, debe entenderse como sinónimo de esencial (Souto, 1996). No obstante, la enseñanza de la Geografía en los colegios del país es parcial, simplista y de un bajo nivel de conocimiento al respecto.

Para superar las limitaciones que atraviesa la enseñanza de la Geografía en las escuelas y colegios del país, debe dejar los elementos tradicionales que la caracterizan como expositiva, descriptiva, de relatos, sin estimulo (Moreno y Marrón, 2000). La enseñanza de la Geografía debe exponer los problemas conociendo su localización, el dominio del espacio a diferentes escalas y con base en la lectura adecuada de mapas. La disciplina, por sus características, exige experiencias y prácticas, que conllevan la vivencia abierta e innovadora del método de la Geografía. Como menciona Lacoste (1996), la Geografía es un conjunto de conocimientos y una forma de razonamiento, que presupone saber pensar el espacio, lo cual permite actuar en forma eficiente respecto de ese saber.

\section{La enseñanza y el aprendizaje de la Geografía}

Si se consideran términos geográficos como espacio, escala, proyecciones, paisaje y erosión y se limita al aprendizaje de ciertas nociones y habilidades, normalmente enseñadas en geografía, surgen las siguientes preguntas: ¿Cómo saber si los estudiantes han aprendido los conceptos? y ¿qué criterios emplear para asegurar que esas nociones han sido asimiladas y forman parte integral del conocimiento del estudiantado? Preguntarse qué se aprende en Geografía, no es una pregunta innecesaria, es fundamental para saber si se transmiten correctamente a nivel didáctico los conceptos geográficos.

Un concepto es sólo el nombre o una palabra para algo; pero algunas veces es útil prenderlo por medio de ejemplos. Así caben las preguntas: ¿es un átomo un concepto?, ¿lo es el salario, el producto interno bruto, el clima o un ecosistema? La respuesta es que todos lo son. Son conceptos, porque son nombres de algo que existe en la realidad, que se han separado del resto de la realidad y a lo que se le ha otorgado una identidad particular. Del conjunto de cosas interconectadas en el mundo real, hay algunas a las que se les da una atención especial, de ese modo, los contenidos de una determinada disciplina giran alrededor de esas partes particulares; así que se crean conceptos para nombrarlas, así como componentes, características o aspectos que se quieren examinar de ellas.

La Geografía como disciplina científica tiene un conjunto de "conceptos" propios que la distinguen, caracterizan y diferencian de otras disciplinas, por lo tanto, crea su propia terminología para una comunicación adecuada. Así, los conceptos de espacio, paisaje, proyección, mapa, depresión y valle son propios de la Geografía. Por ejemplo, las nociones de paso o depresión, valle o ecosistema son un medio para representar ciertas situaciones para clasificarlas dentro de una categoría, sin haber tenido una experiencia personal.

Una persona que vive en Fortuna y Guayabo de Bagaces describe el sitio en que vive como relativamente plano, de poca pendiente, de suelos profundos y fértiles, pero difícilmente comprende y relaciona el sitio en que habita con el concepto de caldera volcánica (Cuadro 1). Igualmente, a un campesino que trabaja la tierra en Orosí, se le hace difícil comprender que el espacio geográfico en que trabaja es un valle fluvial, originado por la acción erosiva y de depositación del río Reventazón. En un 
orden diferente, el concepto de ecosistema no está fundamentado en una simple serie de experiencias personales, sino es el resultado de la relación de un conjunto de conceptos, producto de la reflexión y el análisis de varios investigadores.

\section{Cuadro 1}

Comprensión del concepto de caldera volcánica en estudiantes del colegio de Fortuna y Guayabo de Bagaces

\begin{tabular}{|l|c|}
\hline \multicolumn{1}{|c|}{$\begin{array}{c}\text { Grado de comprensión del } \\
\text { concepto Caldera }\end{array}$} & Porcentaje \\
\hline $\begin{array}{l}\text { Comprendían el concepto en forma } \\
\text { correcta y lo aplicaban al lugar }\end{array}$ & $12 \%$ \\
\hline $\begin{array}{l}\text { Lo relacionaban con la topografía } \\
\text { plana del lugar, pero no lo } \\
\text { comprendían }\end{array}$ & $20 \%$ \\
\hline Ignoraban totalmente el concepto & $60 \%$ \\
\hline $\begin{array}{l}\text { Lo escucharon, pero no lo } \\
\text { comprendían }\end{array}$ & $2 \%$ \\
\hline
\end{tabular}

Fuente: Cuestionario aplicado en junio de 2007.

Por lo anterior, unos conceptos pueden ser más complejos que otros y ello se debe considerar en el aprendizaje, ya que los alumnos jóvenes que no tienen una gran experiencia de vida ni como práctica la observación detallada del entorno geográfico, tienen la tendencia a dar la definición de un concepto con palabras que corresponden a su experiencia más cercana. Un estudio realizado a estudiantes de liceos en Madrid, sobre el término de "terraza fluvial”, mostró que los estudiantes respondieron según el nivel económico y la clase social, ligando el concepto a un entorno inmediato; así, los estudiantes de liceos ubicados en barrios de clase alta dijeron que una terraza era la parte trasera y amplia de la casa, por lo general techada. Por el contrario, los de barriadas obreras, que vivían en multifamiliares respondieron que una terraza era el balcón donde se tendía ropa (Souto, 1996).

Todos los hechos de la Geografía se ubican en un espacio determinado y es necesario recordar que las operaciones mentales para captar los hechos que se dan en el espacio (orden espacial) difieren con la edad, así como de una persona a otra (Castner, 1990). Además, dar a conocer un concepto geográfico a los estudiantes, implica la observación atenta y precisa, capacidad que también varía con la edad. Por esto, los profesores que enfrentan la tarea de comunicar conceptos de Geografía, deben considerar estos aspectos. Para el aprendizaje de conceptos en geografía es importante tomar en consideración la jerarquía cognoscitiva dada por Graves (1984) (Cuadro 2).

Cuadro 2

Jerarquía cognoscitiva de conceptos según Graves

\begin{tabular}{|c|l|}
\hline Nivel & \multicolumn{1}{|c|}{ Definición } \\
\hline I & Representa cosas que uno puede observar \\
\hline II & $\begin{array}{l}\text { Son conceptos que por su dimensión o } \\
\text { situación geográfica raramente son } \\
\text { captados por los estudiantes }\end{array}$ \\
\hline III & $\begin{array}{l}\text { Conceptos que necesitan la comprensión } \\
\text { de otros conceptos previos }\end{array}$ \\
\hline
\end{tabular}

Fuente: Graves, 1984.

Siguiendo la jerarquía cognoscitiva de conceptos de Graves (1984), en el primer nivel se representan cosas que uno puede observar en la vida diaria, por ejemplo: un río, las nubes, una carretera, una ciudad, un campo de cultivo o un supermercado. Estos conceptos se aprenden antes de ir a la escuela, pero el docente puede utilizarlos en sus lecciones, porque forman parte del medio en el cual crecieron los estudiantes. Esta primera categoría se 
relaciona con el aprendizaje de la Geografía en contacto con el medio más próximo. Según Claval (1986), dos de los fundadores de la Geografía moderna se beneficiaron de una educación de este tipo: el alemán Carl Ritter con el profesor Schnepfenthal y el francés Eliseo de Reclus en la escuela pestaloziana que su madre formó en Rotes. Pestalozzi (citado por Claval, 1986) dice que la observación y el aprendizaje a través del medio próximo constituyen una herramienta de gran utilidad y Claval finaliza planteando que es bien conocido el éxito de este tipo de pedagogía, basada en la aprensión de lo más próximo o conocido en los estudios del medio dentro de la Geografía moderna.

En el segundo nivel, Graves (1984) incluye conceptos que por su dimensión o situación geográfica raramente son captados por los estudiantes. Reagrupa e incluye los conceptos que representan cosas concretas, pero que, a causa de su situación geográfica o a causa de de su magnitud, raramente entran en la experiencia de los alumnos. Dentro de esta categoría se incluyen los conceptos de: continente, tundra, valle, terraza marina y huracán; evidentemente, la lista varía según el medio donde se localice la escuela o colegio. En este segundo nivel percibe y comprende mejor el concepto de volcán una persona que vive cerca del volcán Arenal que una que habita en playa Tamarindo.

El tercer nivel de Graves (1984) comprende conceptos que necesitan la comprensión y el dominio de conceptos previos. Esta categoría reúne los conceptos que necesitan el conocimiento de otros conceptos, para captarlos y entenderlos de manera satisfactoria. Uno de los más sencillos es el concepto de densidad de la población, que establece la relación entre una población y la superficie del territorio que la contiene. Otro es la noción de relieve, que requiere de elementos como pendiente, altitud y forma.

La simplicidad o complejidad de los conceptos depende del número de variables o elementos integrados. Por ejemplo, un concepto complejo es el de viento alisio, en el cual hay que considerar y dominar varios conceptos previos como presión atmosférica, anticiclón o alta presión, depresión o baja presión, fuerza de coriolis y gradiente barométrico. En este caso, cada elemento exige una comprensión de otra noción: la presión atmosférica necesita del conocimiento de alta y baja presión, características térmicas del aire, efecto de rotación de la Tierra. Finalmente, el concepto de viento alisio es producto de una interrelación sistémica de todos estos procesos. Estos tipos de conceptos y su comprensión son muy difíciles para la mayoría de estudiantes, maestros y profesores de Estudios Sociales.

Otros conceptos del tercer nivel son el de subducción y el de proyección cartográfica. El de subducción requiere del dominio de conceptos, tales como: placa tectónica, convección, tipos y constitución de las placas, astenosfera, corrientes de convección y fosa tectónica. El concepto de proyección cartográfica implica el dominio de conceptos tales como: geoide, elipsoide, esfera, proyección, plano, mapa y escala.

El aprendizaje humano se ajusta a cierto orden de sucesión que va, por lo general, de lo concreto a lo abstracto y de lo particular a lo general, y no puede ser alterado. Naish (1989) considera que los conceptos de observación u obtenidos por medio de la observación se adquieren con mayor facilidad, mientras los conceptos por definición son más complejos y difíciles. Al respecto, el concepto de paisaje es un término clave de la Geografía, muy utilizado en las escuelas de Geografía de las universidades y en la enseñanza secundaria. La noción de paisaje es muy compleja, porque su contenido es amplio, integrador y sistémico (Bertrand, 1978; Rougerie y Beroutchachvili, 1991), por eso se seleccionó el concepto de paisaje para conocer la representación mental 
del paisaje y cómo construyen y utilizan los estudiantes de colegio dicha representación mental.

Para la investigación referida, se elaboró un cuestionario con tres preguntas sobre el concepto de paisaje. Como apoyo se suministró a los estudiantes dos fotografías que representaban un paisaje natural en equilibrio y un paisaje con influencia antrópica (foto $1 \mathrm{y}$ foto 2). El cuestionario se aplicó a un total de 100 estudiantes de sétimo año y 100 estudiantes de undécimo año, de colegios públicos y privados de la Gran Área Metropolitana de Alajuela, Heredia, San José y Cartago.

Las tres preguntas que se plantearon fueron las siguientes.

1. ¿Escriba una definición de paisaje?

2. ¿Cuáles son los principales elementos que componen cada uno de los paisajes?

3. ¿Represente por medio de un gráfico las relaciones que se establecen entre los elementos del paisaje?

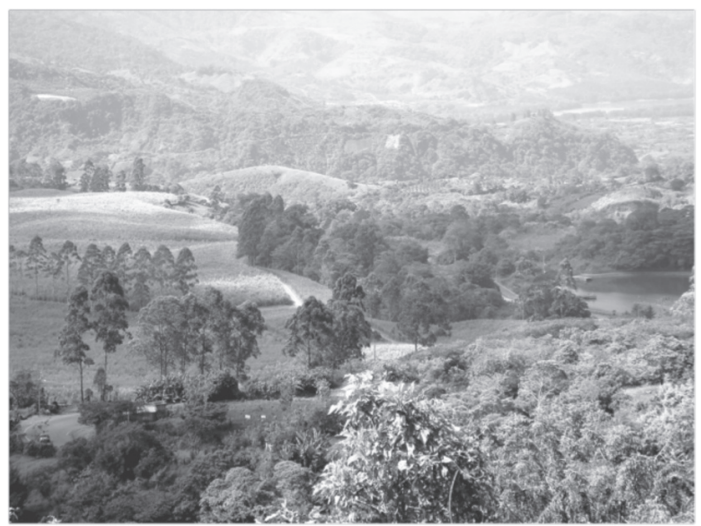

Foto 1: Paisaje cultural: Cultivo de caña de azúcar sobre la colada de Cervantes cerca de la población de Juan Viñas.

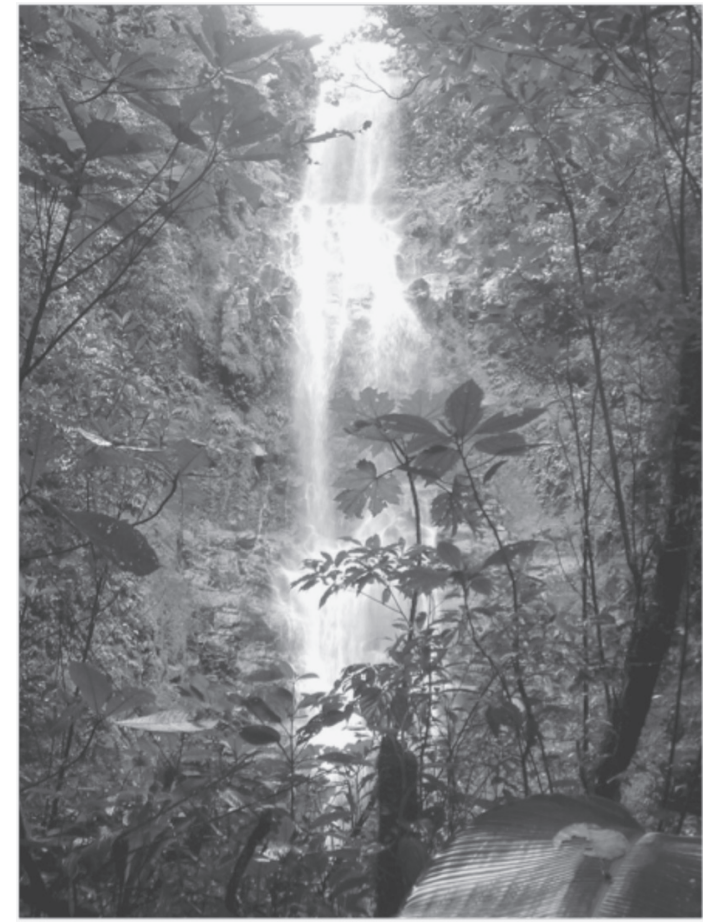

Foto 2: Paisaje natural: Bosque muy húmedo tropical submontano y catarata en el volcán Santa María.

Al analizar las respuestas de los estudiantes resaltan tres aspectos importantes. Primero, el concepto de paisaje se reduce a elementos naturales, así el $89 \%$ de los elementos citados en sétimo y el $80 \%$ en undécimo son elementos naturales, dominando entre ellos el clima y la vegetación (ver Figura 2). Igualmente, llama la atención cómo los animales, el suelo, el viento y el relieve se citan en un $3 \%$ y solo 11 estudiantes de sétimo y 17 de undécimo citaron elementos antrópicos.

Elementos que componen el paisaje según estudiantes de sétimo.

El segundo aspecto relevante es que al definir el concepto de paisaje, los elementos citados aparecen en forma aislada. El $100 \%$ de los estudiantes de sétimo y el $90 \%$ de undécimo usaron elementos aislados, siempre con dominio de los elementos físicos y solo el $10 \%$ de estudiantes en undécimo los presentaron en forma integrada (ver Figura 3). 
Figura 2

Elementos que componen el paisaje según estudiantes de sétimo

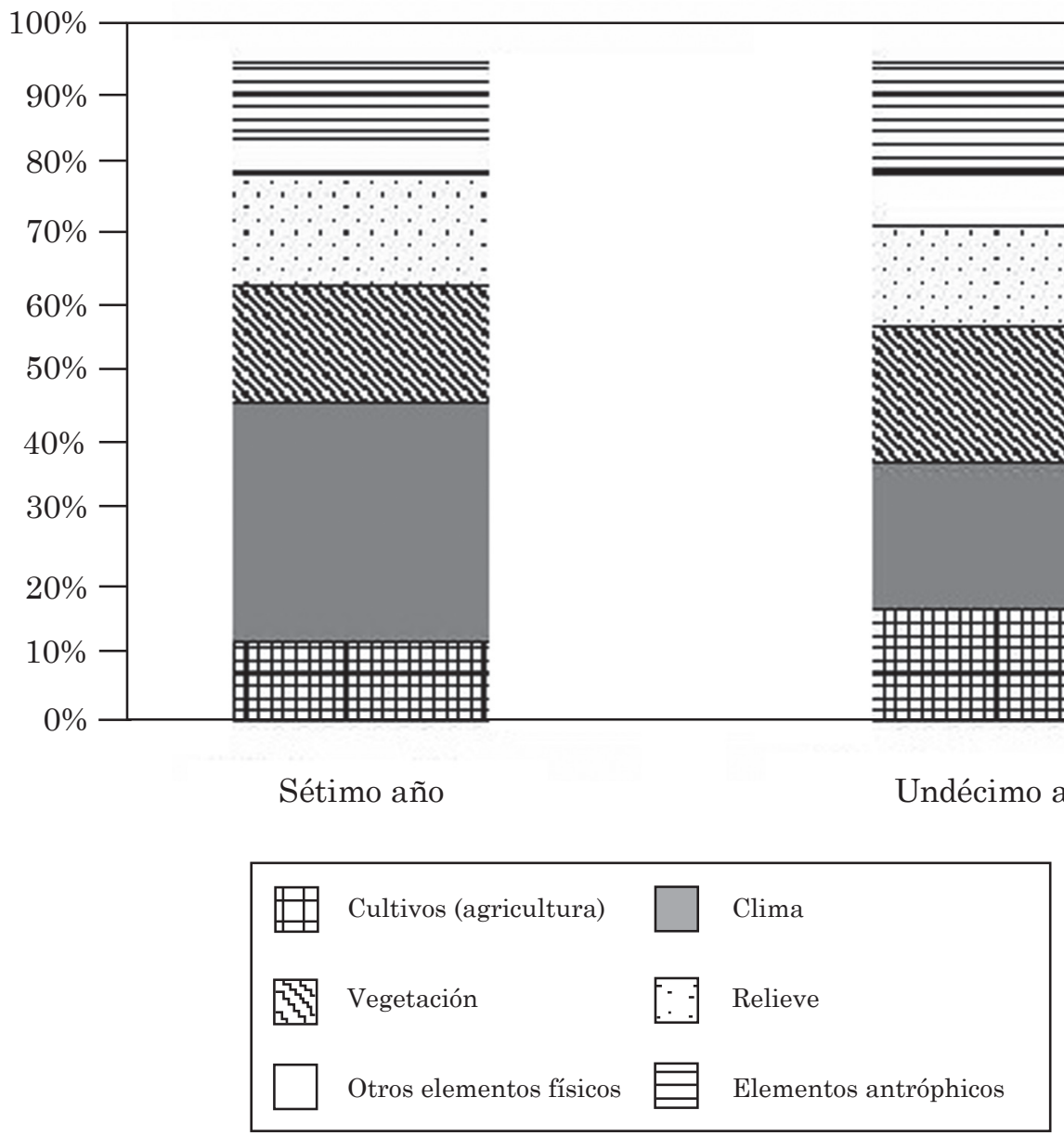

Fuente: Encuesta del autor.

Integración de los elementos al definir el paisaje.

El tercer aspecto relevante fue que la integración de los elementos que componen el paisaje se presenta únicamente en estudiantes de undécimo. Ello se puede explicar por un mejor aprendizaje y cierto dominio de los conceptos adquiridos durante los cinco años de colegio; sin embargo, las relaciones se establecen en una sola dirección, de un elemento a otro y de manera incompleta, faltando gran cantidad de elementos. La mejor representación gráfica realizada por un estudiante se hizo por medio de la Figura 4, donde se pueden observar que las relaciones más frecuentes se dan entre temperatura, lluvia, suelo y vegetación. La actividad humana por medio de los cultivos se relaciona únicamente con el suelo (ver Figura 4). 
Figura 3

Integración de los elementos al definir el paisaje.

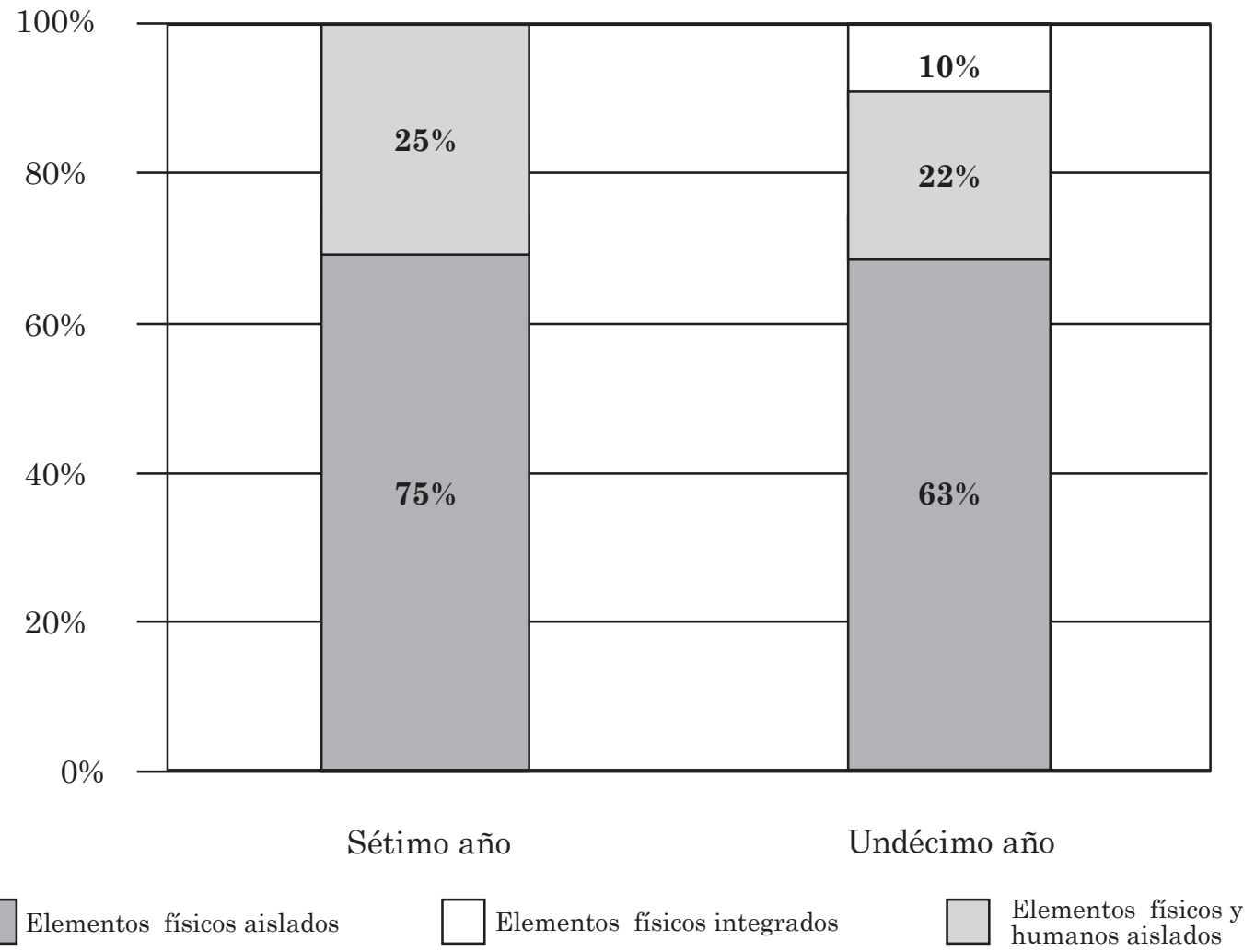

Fuente: Encuesta del autor.

Figura 4

Relaciones establecidas en un paisaje por un estudiante de undécimo año

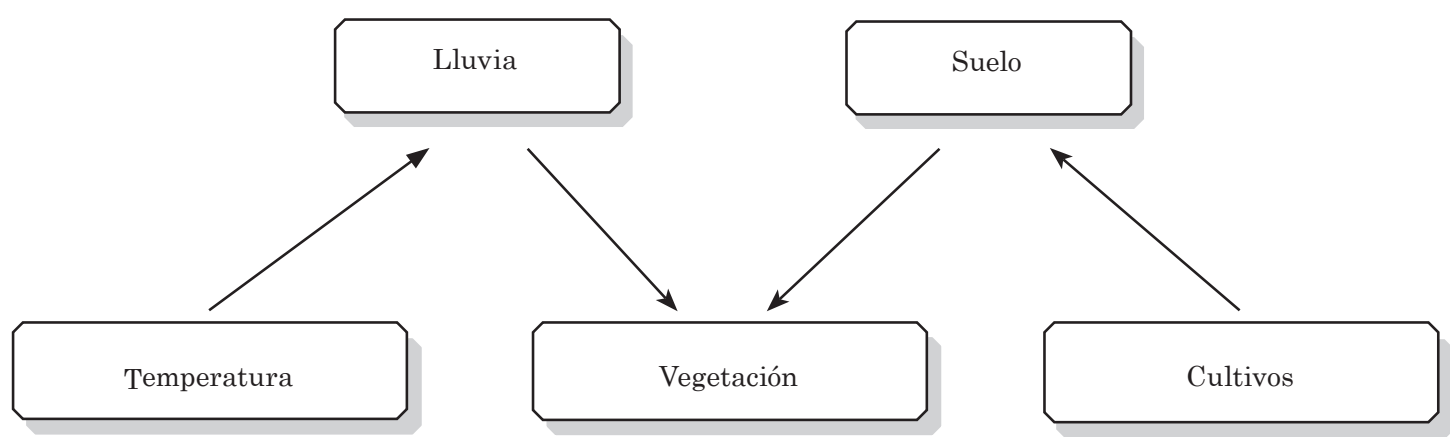

Fuente: Encuesta del autor. 
Los resultados anteriores son consecuencia de las limitaciones en didáctica de la geografía del profesorado.

Desde sétimo a undécimo año se habla a los estudiantes de paisaje, pero en escasas ocasiones se define apropiadamente el concepto. Bertrand (1968), Bertrand y Dollfus (1973) y Tricart y Killian (1985) definen el paisaje como una porción de la superficie terrestre que ha sido el resultado de la combinación dinámica, por tanto, inestable, de elementos físicos, bióticos y antrópicos que actúan de forma interconectada los unos con los otros y hacen del paisaje un conjunto único, en constante evolución.

De esa definición interesa resaltar conceptos claves que particularizan el objeto de estudio. En tal sentido, se destaca en primer lugar la condición de conjunto, ya que todo paisaje es un todo y no la suma de partes; en segundo lugar, la interacción de los elementos, porque están integrados por componentes de distinta naturaleza, dependientes entre sí; en tercer lugar, el dinamismo o funcionalidad que se define por flujos de entrada y salida de energía y materia en el sistema; en cuarto lugar, el espacio que posee una escala territorial; y, en quinto lugar, el tiempo o escala temporal. De acuerdo con la definición anterior de paisaje, se puede concluir del estudio con estudiantes de secundaria que se mencionó anteriormente al respecto, que en la enseñanza secundaria de Costa Rica no ha sido verdaderamente construido ni interiorizado por los alumnos de sétimo y undécimo año el concepto de paisaje.

Piaget (1978) considera que es difícil la enseñanza de un pensamiento abstracto o hipotético deductivo antes que los alumnos tengan la madurez necesaria para comprenderlos. A este propósito, se han dado varias edades para ese nivel de madurez; sin embargo, Rhys (1972), en un estudio realizado en colegios de Inglaterra en las clases de Geografía, sugiere que es poco útil transmitir los conceptos abstractos antes de los catorce años de edad para el caso de la Geografía. Entre ese tipo de conceptos se pueden citar los siguientes: viento, tectónica, corrientes de convección, latitud, longitud, proyección, relieve, entre otros.

Souto (1996) llama "teorías" a los medios para explicar ciertos fenómenos. En geografía física, la teoría que explica los movimientos de los continentes y la formación de montañas es la tectónica de placas. En Geografía humana la teoría que explica la jerarquía de las ciudades y su distribución en el espacio es la de Christaller. Lo importante en el aprendizaje de la geografía es reconocer que las teorías son explicaciones provisionales y parciales, que no explican todas las manifestaciones de los fenómenos. Pese a esta realidad, en los libros de texto que se usan en las escuelas y colegios del país en la actualidad, raramente se resalta el carácter provisional y parcial de las teorías. Un ejemplo concreto de esta omisión son las clasificaciones climatológicas, pues pese a que existen múltiples clasificaciones del clima, en la enseñanza secundaria solamente se considera la de Koppen y no se aclara que no es la única teoría disponible al respecto. De esta manera, se cierra la posibilidad de que el estudiantado conozca otras teorías y que se estudien las limitaciones y ventajas de las diferentes clasificaciones climatológicas.

Las teorías pueden tener diferentes grados de dificultad y ser tratadas en forma superficial o profunda. Por ejemplo, se puede explicar que llueve más en las regiones de montaña que en las llanuras, por medio del fenómeno de enfriamiento de una masa de aire que es obligada a ascender por el obstáculo del relieve, conocido como efecto orográfico; pero, si se pregunte cómo se forman las gotas de lluvia y por qué no se mantienen en suspensión dentro de la nubes, aparece en este caso otro marco explicativo o teoría.

En el Ministerio de Educación Pública no se ha considerado hasta ahora la jerarquía cognoscitiva en el diseño y ejecución de los programas de Estudios Sociales (véase al respecto el Cuadro 2), 
y es aquí donde se inicia una cadena de problemas en la transmisión y enseñanza de los conceptos de Geografía a los estudiantes. En consecuencia, es necesario que los programas de Estudios Sociales para primaria y secundaria, tomen en cuenta la jerarquía cognoscitiva para hacer una distinción entre los conceptos que representan objetos concretos, que los estudiantes pueden aprender por observación directa o indirecta, y los conceptos que representan nociones más abstractas que el profesor debe exponer y explicar con un excelente dominio conceptual y didáctico.

\section{La formación de profesores de Estudios Sociales y la enseñanza de la Geografía en Costa Rica}

La formación de profesores de secundaria del área de Estudios Sociales en universidades públicas y privadas del país, es parte de carreras compartidas en las que se incluyen cursos de Geografía, Historia y Educación. Lo lógico en una carrera compartida es que cada una de las disciplinas que componen el plan de estudios participe de un tercio de las asignaturas, pero esto no es así. En términos generales, la geografía ocupa entre un $12,2 \%$ y un $17,7 \%$ de los cursos (ver Cuadro 3). Este bajo porcentaje de la formación en la especialidad, conlleva conocimientos restringidos y fragmentados al respecto, ya que no se abarcan áreas tan importantes como Geomorfología, Climatología, Vegetación, Cartografía y Geología, temas que el docente debe cubrir en los programas de estudios de sétimo a undécimo año.

Cursos de Geografía en los programas de estudio de la enseñanza de los estudios sociales en universidades públicas y privadas de Costa Rica

Es de resaltar la ausencia de cursos de Cartografía en todas las universidades, excepto la Universidad de Costa Rica. No es posible formar profesores en
Estudios Sociales sin contar con un curso de Cartografía, porque esta materia y la comprensión de los mapas son el principal instrumento de trabajo en Geografía. $\mathrm{Al}$ respecto, cabe preguntarse ¿cómo un profesor de Estudios Sociales que no tuvo formación en Cartografía puede impartir el tema 2 del programa de sétimo año: Generalidades cartográficas en la enseñanza de los Estudios Sociales? y ¿cómo puede desarrollar las temáticas de los otros niveles sin aplicar los conceptos cartográficos y realizar prácticas en mapas?

En ninguna de las universidades privadas se dan cursos de Geografía de América, lo que crea una carencia fundamental para impartir todo el contenido del programa de octavo año, que es sobre geografía física y cultural de América. Estos cursos sí los tienen la Universidad de Costa Rica y la Universidad Nacional. La Geografía Mundial con enfoque regional aparece en los programas de noveno año y de décimo año en el tema de modos de vida. El enfoque regional en Geografía consiste en desarrollar temáticas en regiones que tienen características propias y homogéneas, que las hacen diferentes de otras áreas vecinas. Este enfoque solo se imparte en las dos universidades estatales, mientras que las privadas siguen la Geografía Mundial tradicional, por continentes individuales.

Los profesores de Estudios Sociales deben cumplir con programas que les exigen conocimientos de Climatología, Geomorfología, Geología y Demografía, pero las universidades responsables de preparar al personal docente de Estudios Sociales no los forman en esas temáticas y se hace énfasis en cursos de Geografía regional como América Latina, América Central, Mundial y Costa Rica, pero no en cursos que formarían y fortalecerían la formación de los profesores en contenidos y conceptos propios de la disciplina.

Parafortalecerlosaspectosconceptuales en la formación del profesorado, un curso de Fundamentos de Geología brindaría una buena formación en aspectos de tectónica 


\section{Cuadro 3}

Cursos de Geografía en los programas de estudio de la enseñanza de los estudios sociales en universidades públicas y privadas de Costa Rica

\begin{tabular}{|c|c|c|c|c|}
\hline Universidad & $\begin{array}{l}\text { Total de cursos } \\
\text { del programa }\end{array}$ & $\begin{array}{l}\text { Número de } \\
\text { cursos de } \\
\text { geografía }\end{array}$ & $\begin{array}{l}\text { Porcentaje de } \\
\text { cursos de } \\
\text { geografía en el } \\
\text { programa de } \\
\text { estudios }\end{array}$ & Cursos de Geografía \\
\hline $\begin{array}{l}\text { Universidad } \\
\text { de Costa Rica } \\
\text { (PÚBLICA) }\end{array}$ & 45 & 8 & 17,7 & $\begin{array}{l}\text { - Análisis geográfico } \\
\text { - } \text { Cartografía básica } \\
\text { - Geografía de Costa Rica } \\
\text { - Geografía de América Latina } \\
\text { - Geografía regional mundial } \\
\text { - Geografía de América Central } \\
\text { - } \text { Giografía política } \\
\text { Beografía }\end{array}$ \\
\hline $\begin{array}{l}\text { Universidad } \\
\text { Nacional } \\
\text { (PÚBLICA) }\end{array}$ & 45 & 6 & 13,3 & $\begin{array}{ll}\text { - } & \text { Fundamentos de geografía } \\
\text { - } & \text { Geografía regional mundial } \\
\text { - } & \text { Geografía de Costa Rica } \\
\text { - } & \text { Formación y dinámica terrestre } \\
\text { - } & \text { Geografía ambiental y riesgos }\end{array}$ \\
\hline $\begin{array}{l}\text { Universidad } \\
\text { Americana } \\
\text { (PRIVADA) }\end{array}$ & 33 & 4 & 12,2 & $\begin{array}{ll}\text { - } & \text { Geografía Mundial I } \\
\text { - } & \text { Geografía Mundial II } \\
\text { - } & \text { Geografía Mundial III } \\
\end{array}$ \\
\hline $\begin{array}{l}\text { Universidad } \\
\text { Católica } \\
\text { (PRIVADA) }\end{array}$ & 34 & 5 & 14,7 & $\begin{array}{l}\text { - Geología, } \\
\text { - Historia natural de Costa Rica } \\
\text { - Geografía de Costa Rica } \\
\text { - Geografía de América } \\
\text { Geografía de Europa, Asia, } \\
\text { África y Oceanía. }\end{array}$ \\
\hline $\begin{array}{l}\text { Universidad } \\
\text { Latina } \\
\text { (PRIVADA) }\end{array}$ & 32 & 4 & 12,5 & $\begin{array}{l}\text { - Geografía Mundial I Geografía } \\
\text { Mundial II } \\
\text { - Geografía Mundial III Geografía } \\
\text { de Costa Rica }\end{array}$ \\
\hline
\end{tabular}

Fuente: Programas de estudio de la Universidad de Costa Rica, Universidad Nacional, Universidad Americana, Universidad Católica, Universidad Latina.

de placas y tipos de rocas; un curso de Geomorfología para conocer las formaciones de los relieves terrestres y sus transformaciones, uno de climatología para entender los procesos climatológicos como los sistemas de vientos, ondas tropicales, huracanes, depresiones, frentes fríos y régimen de lluvias y un curso de Biogeografía aportaría conocimientos de vegetación, zonas de vida, ecosistemas, paisajes naturales. $\mathrm{Al}$ respecto, la Universidad de Costa Rica es la que tiene un mayor número de cursos temáticos como
Cartografía, Geografía política, Biogeografía, seguida por la Universidad Nacional y la Universidad Católica con dos cursos. Las restantes no tienen cursos temáticos.

Como se puede observar, la enseñanza de la Geografía en la formación del profesorado de Estudios Sociales en las universidades analizadas es incompleta y carente de cursos temáticos fundamentales y es probable que la ausencia de esos contenidos incida en la forma como se manejan los conceptos de geografía, que muestran 
graves errores o se desconocen del todo. La mala formación del profesorado es el principio de una cadena de errores en la transmisión y enseñanza de los conceptos de Geografía. Para comprobar esta afirma- ción se hizo una investigación, con base en un cuestionario de seis preguntas, dos por cada tema, que se aplicó a 50 profesores del cantón Central de San José, Guadalupe, Montes de Oca y La Unión (Cuadro 4).

\section{Cuadro 4}

Cuestionario temático aplicado a profesores de Estudios Sociales, cantones de San José, Guadalupe, Montes de Oca y la Unión

1. Las lluvias monzónicas que afectan al sur y sureste de Asia se originan por:
a. ( ) el bloqueo que ejercen los Himalayas a los vientos del fríos del Norte
b. (x) al ascenso en latitud de bajas presiones del océano Indico
c. ( ) la llegada de vientos alisos del suroeste

2. La canícula es una disminución de lluvias en el mes de julio en la vertiente Pacífica de Costa Rica que es provocado por:
a. (x) el desplazamiento de la ZCIT al sur de Costa Rica y la incursión del alisio del Noreste
b. ( ) la disminución de los alisios del Suroeste al encontrarse la ZCIT sobre Costa Rica
c. ( ) la formación de bajas presiones en el mar Caribe

3. Las rocas metamórficas son:
a. ( ) rocas ígneas extrusivas originadas de lavas volcánicas
b. (x) originadas a partir de rocas sedimentarias por medio de presión y calor
c. ( ) son originadas por depósitos de piroclastos

4. La cordillera de Talamanca no presenta en la actualidad un vulcanismo activo a causa de:
a. (x) un cambio en el ángulo de subducción de la placa de Cocos
b. ( ) la intrusión del batolito
c. ( ) la poca profundidad de la fosa Mesoamericana

5. Las zonas de vida se definen por medio de variables climáticas y representan a la vegetación que:
a. ( ) existe en la actualidad
b. ( ) se recupera después de una deforestación
c. (x) que existiría en ausencia del ser humano

6. Los bosques nubosos de alta montaña se conocen con el nombre de:
a. ( ) bosques hidrófilos
b. (x) bosques higrófilos
c. ( ) bosques xerófilos

Se representa MARCA con una X la respuesta correcta

Fuente: Elaboración del autor. 
Los resultados del cuestionario fueron alarmantes, por el alto porcentaje de respuestas erradas (Fig. 5). El porcentaje de resultados equivocados fue superior al $78 \%$ en todas las preguntas, llegando hasta un $98 \%$ en la pregunta número 5. Lo anterior muestra la necesidad de hacer cambios en la formación del profesorado de Estudios Sociales, fortaleciendo los cursos temáticos que proporcionan una sólida formación para el manejo conceptual y para impartir lecciones más analíticas y menos descriptivas.

Figura 5

Resultado del cuestionario temático aplicado a profesores de estudios sociales

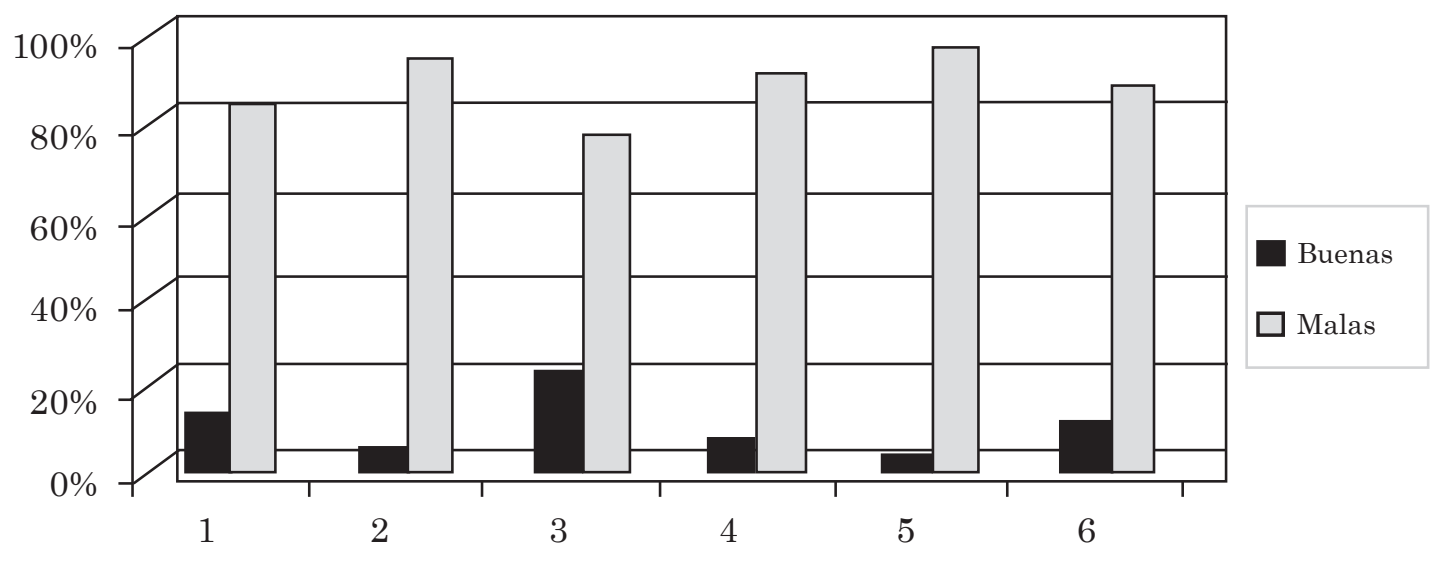

\# de pregunta

Fuente: Encuesta del autor.

\section{Estrategias y recursos didácticos en Geografía}

Para transmitir y comprender los diversos componentes físicos y culturales de la Geografía, se recurre a diferentes estrategias y recursos didácticos como el trabajo de campo, las prácticas de laboratorio, la enseñanza con computadora, los medios audiovisuales como la fotografía, las diapositivas, el vídeo, la radio, las fuentes literarias y documentales, los mapas, las fotografías aéreas, las imágenes satélite y las estadísticas.

En Costa Rica, en especial en la enseñanza de la Geografía, en el Tercer Ciclo y la Enseñanza Diversificada no se cuenta con los medios para llevar a cabo la totalidad de las estrategias didácticas mencionadas, excepto en algunos colegios privados. Al margen de los recursos, en general, en instituciones públicas y privadas se presentan las limitaciones y deficiencias señaladas en la formación del profesorado, con la consecuente insuficiencia para llevar a la práctica estrategias didácticas apropiadas para la enseñanza de la Geografía. En este caso, se analizarán cinco recursos didácticos accesibles para la mayoría de las instituciones de secundaria del país. Ellos son: el uso de la Cartografía, la Estadística, las fuentes literarias, los periódicos y revistas, y la escala. Si bien es cierto, el trabajo de 
campo es de vital importancia en la enseñanza de la Geografía, existen normativas del Ministerio de Educación Pública que limitan la realización de esta actividad.

\subsection{El uso de la cartografía}

La información que reciben profesores, profesoras y alumnos tiene un grado de dificultad. En el caso de la Geografía la dificultad aumenta por la variedad de códigos lingüísticos utilizados, dado que el conocimiento de la disciplina se transmite en lenguajes cartográficos, estadísticos, icónicos y verbales. La más antigua de las tres es la cartografía que nació con la Geografía, resultado de la observación del mundo y del deseo de representar la forma de la Tierra y los continentes, y de medir los itinerarios trazados.

La cartografía es una disciplina que integra ciencia, técnica y arte, representa la superficie de la Tierra sobre un mapa, valiéndose de un sistema de proyecciones para pasar de la esfera al plano. En el mapa se representan elementos físicos o tangibles como los ríos, poblaciones, carreteras, vías férreas y elementos ficticios o ideados por los geógrafos, que no pueden observarse en el terreno, pero son tan reales como los elementos físicos que se representan en el mapa: los paralelos, meridianos, límites provinciales o entre países.

Como se mencionó, la cartografía es la base del análisis geográfico. El mapa es el instrumento que distingue a la Geografía y es su lenguaje específico, pese a ello, los docentes, al impartir las clases de Geografía, casi no utilizan el mapa como medio preponderante en la recepción y transmisión de la información geográfica. Ello se explica porque en la formación universitaria del profesorado de Estudios Sociales, no se utiliza la cartografía como una forma de comunicación de los contenidos geográficos; de ahí el poco uso y aplicación que hacen los profesores de Estudios Sociales de los mapas en las aulas.
En Costa Rica, en particular en la enseñanza de la Geografía, el mapa debe convertirse en un documento primordial, no así la fotografía aérea ni las imágenes de satélite, que son menos accesibles o no accesibles del todo en los colegios, por carecer de medios económicos, instrumentos para su análisis y porque los profesores de Estudios Sociales enfrentan grandes limitaciones en su formación profesional para utilizarlas.

En la enseñanza de la Geografía desde sétimo hasta undécimo año, solo se imparte Cartografía en el sétimo nivel, bajo el título de: Generalidades cartográficas en la enseñanza de los Estudios Sociales. Al respecto, los objetivos, procedimientos y el aprendizaje a evaluar son descriptivos y siguen una Geografía tradicional, donde predomina la localización y el manejo memorístico de conceptos, porque no se desarrollan actividades con el mapa, ni se estimula la lectura e interpretación de ellos (Ver Cuadro 5). Los profesores y profesoras, por lo general, no vuelven a utilizar la Cartografía en los niveles superiores, ignorando que ella y el uso de mapas facilitan la transmisión de los conceptos y conocimientos importantes, tales como formas de relieve, densidad de población, cuencas hidrográficas, características de los ríos y otros.

El mapa se solicita en secundaria, en la mayoría de ocasiones, para localizar lugares, pero no para leerlo o interpretarlo; por ejemplo, se desconoce que la escala cromática es una forma de representar la altitud y curvas de nivel y que con ellos se pueden hacer perfiles topográficos. Para trabajar con la Cartografía en la clase es necesario que el alumno o alumna se percate de que el mapa es una representación de la realidad, pero no es la realidad misma. Ello implica que el estudiantado debe reconocer el simbolismo con el que se dibujan y representan las formas tridimensionales (Boardman, 1986; Comes, 1993).

La representación geométrica, convencional y plana de los mapas es muy difícil de descubrir por el alumnado. El profesor o profesora puede señalar que el 


\section{Cuadro 5}

Contenidos de la Cartografía en el programa de Estudios de sétimo año

Tema II: Generalidades cartográficas en la enseñanza de los Estudios Sociales

\section{Objetivos}

Analizar la importancia del aprendizaje de los Estudios Sociales y de los aportes de las disciplinas auxiliares

\section{Contenidos}

Generalidades cartográficas en la enseñanza de los Estudios Sociales.

Cartografía: concepto e importancia.

Formas de representación de la tierra.

$$
\begin{array}{ll}
\text {. } & \text { La esfera } \\
\text {. } & \text { El mapa } \\
\text {. } & \text { Definición }
\end{array}
$$

Tipos: temáticos y generales.

Elementos: simbología, coordenadas geográficas y escala.

Lectura e interpretación de mapas.

- Escalas: gráfica y numérica.

- Coordenadas geográficas: paralelos y meridianos

- Simbología

\section{Procedimientos}

Relación del mapa con el espacio terrestre, interpretación del vocabulario cartográfico, explicación del uso y la importancia de la cartografía, identificación de las diferentes formas de representación de la Tierra, interpretación de los tipos, los elementos y la simbología del mapa, ubicación de sitios geográficos utilizando las coordenadas geográficas y las diferentes escalas, ejemplificación del empleo de la escala y las coordenadas para la ubicación de sitios geográficos, comprensión de la importancia del empleo correcto de la cartografía.

\section{Aprendizaje para evaluar}

Comprensión de las nociones cartográficas que permiten la localización de sitios geográficos, la orientación y el desplazamiento en los espacios terrestres.

Fuente: Costa Rica, M.E.P. (2003). Programa de Estudios Sociales para sétimo año.

color café representa las montañas y que el cerro Chirripó, ubicado en la cordillera de Talamanca, es el punto más elevado de Costa Rica, que también se representa en el mapa con el color café; pero, lo que observa el estudiante es un plano con color café, con un símbolo de un triangulo que representa el Chirripó y un número 3820, que determina la altitud, por lo que muy pocos son capaces de determinar el volumen y la forma tridimensional de los elementos geográfico dentro del mapa. 
Los mapas son fuentes de información complejas. Todo mapa está hecho por medio de tres signos: puntos, líneas y superficies (Souto, 1996). Dentro de ellos, Los signos adquieren un simbolismo por medio del color, el tamaño o la tonalidad que permiten determinar líneas de igual altitud (isolíneas), ríos, fronteras, el trazado del ferrocarril, topónimos, aeropuertos y poblaciones de diversos tamaños. Otro elemento explicativo en los mapas, además de los signos y símbolos, es la escala, pues según sea esta, así será el significado simbólico de los puntos y líneas. Dada su complejidad, para leer y comprender un mapa es necesario:

1. Enseñar al estudiante a identificar y manejar los símbolos básicos.

2. Una vez que el estudiante es capaz de identificar los signos básicos, debe interpretar las formas espaciales y analizar las características de la superficie; por ejemplo, si es plana o montañosa, alta o baja, entre otros.

En sétimo año se debe usar un mapa de Costa Rica para impartir los contenidos de Geografía y en especial de Cartografía. El mapa que se recomienda por su calidad y buena representación es el mapa escolar de Costa Rica del Instituto Geográfico Nacional, a escala 1: 1000000 y 1: 1500 000. El primer paso en el mapa de Costa Rica a escala 1: 1500000 o 1: 1000000 del Instituto Geográfico Nacional es identificar que el río Tempisque y el río Savegre se representan con una línea azul; el segundo paso es más difícil y puede hacerse directamente en el mapa o realizando perfiles. Los perfiles topográficos de los ríos Tempisque y Savegre (ver Figuras 6 y 7) permiten observar, distinguir y determinar las siguientes características:

a. Que el río Savegre nace a una mayor altitud que el río Tempisque.

b. Que el río Savegre tiene un recorrido más largo en montaña y muy corto en llanura, mientras que el Tempisque es todo lo contrario.

c. Finalmente se pueden deducir los posibles usos de los ríos: el Pirrís es un río para uso hidroeléctrico y el Tempisque para navegación.

Figura 6

Perfil del río Savegre

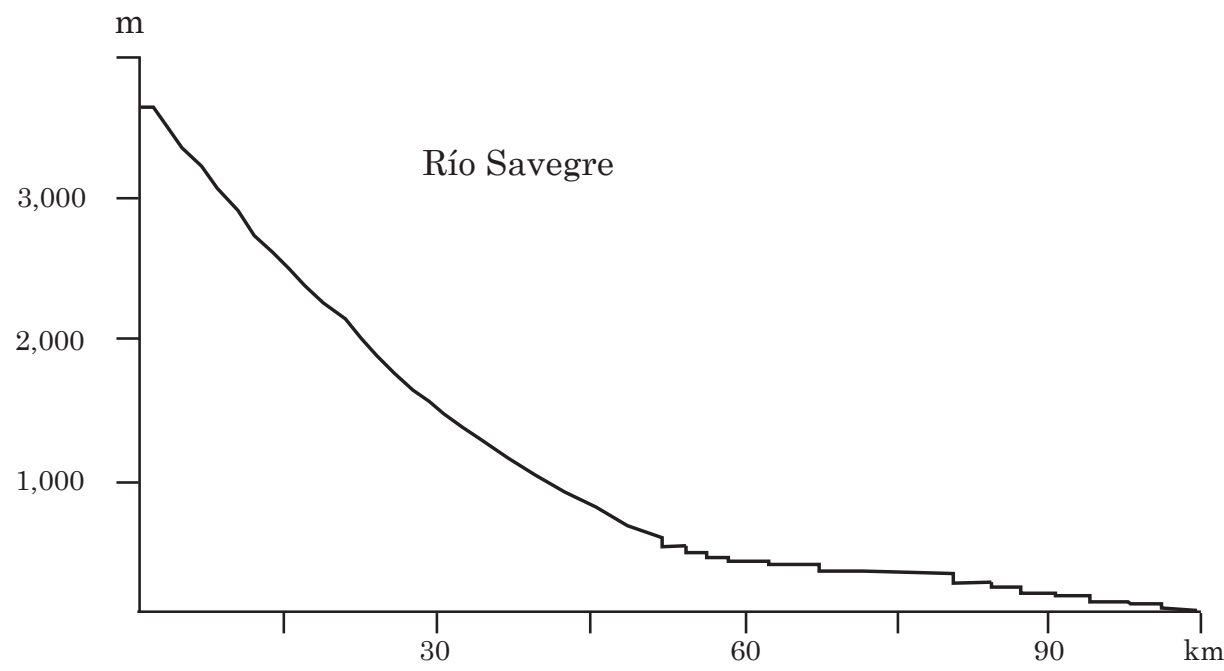

Fuente: IGN. 2002. Mapa Escolar de Costa Rica. Escala 1:1 500 000. San José. 
Figura 7

Perfil del río Tempisque

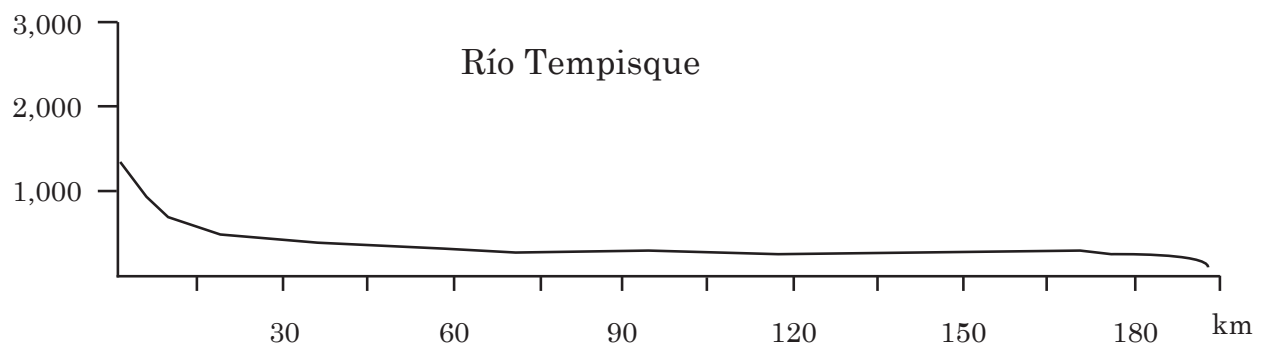

Fuente: IGN. 2002. Mapa Escolar de Costa Rica. Escala 1:1 500 000. San José.

Los perfiles topográficos realizados a partir del mapa escolar de Costa Rica o de otras regiones del mundo permiten distinguir formas de relieve que en el plano de un mapa son difíciles de observar, como que el volcán Arenal se ubica en la depresión tectónica de Arenal (Figura 8) o la topografía de meseta en los macizos de Guyana y Matto Grosso (Figura 9).

La elaboración de mapas temáticos con la ayuda de bases de datos, fáciles de obtener en instituciones gubernamentales como el Instituto Nacional de Estadística y Censos (INEC), Ministerio de Salud o en publicaciones como el Estado de la Nación y el Almanaque Mundial son un recurso didáctico muy importante para visualizar problemas en el espacio (ver Figuras 10 y 11).

\subsection{El uso de la estadística en el aprendizaje geográfico}

La estadística es la disciplina que se ocupa de la recolección, agrupación, presentación, análisis e interpretación de datos, lo que le permite actuar como puente o unión entre la realidad y la teoría (Audigier, 1997). Es necesario unir los contenidos explicados en clase a la realidad, no sólo para responder a la "tradicional" pregunta de los alumnos: ¿y esto para qué sirve?, sino para dar sentido y efectividad a la labor docente. Esa unión se puede realizar por medio del uso de datos estadísticos y gráficos, en especial para el desarrollo de temas como Climatología, Demografía, Geografía de la población y la Geografía Económica (Boardman, 1986).

Para el desarrollo de temáticas sobre el clima, la población y con aspectos económicos como la industria, el comercio y el turismo, también es indispensable el uso de la estadística (Buffet, 1986; Moreno y Marrón, 2000); sin embargo, al analizar los libros de texto utilizados en la enseñanza de la Geografía en el Tercer Ciclo y en la Enseñanza Diversificada de Costa Rica, se observa que los datos estadísticos están casi ausentes en cuadros y gráficos, y si aparecen son ilustrativos y no se realiza ninguna actividad o práctica con ellos. 
Figura 8

Perfil tectónico de Arenal

Depresión Tectónica del Arenal
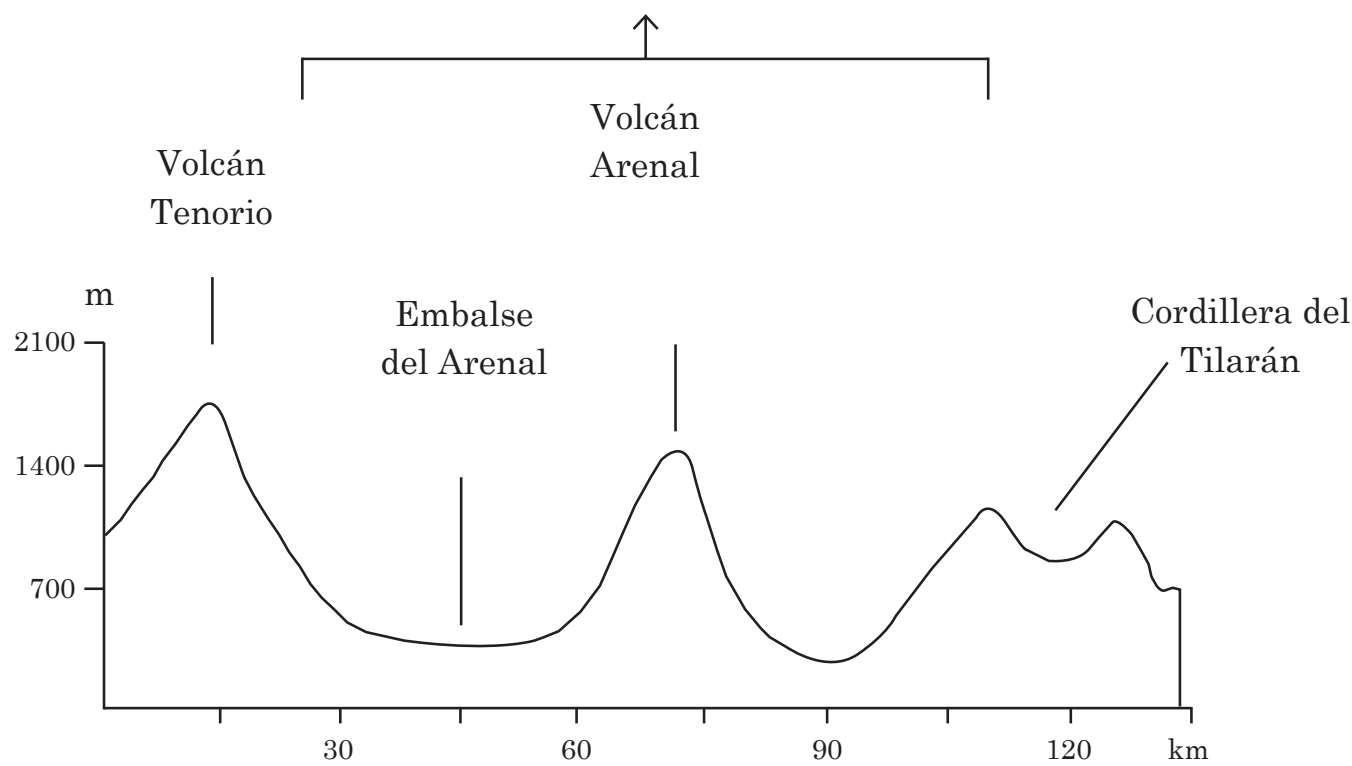

Fuente: IGN. 2002. Mapa Escolar de Costa Rica. Escala 1:1, 500 000. San José.

Figura 9

Perfil topográfico de Macizo de Guayana, llanura Amazónica y macizo Brasileño

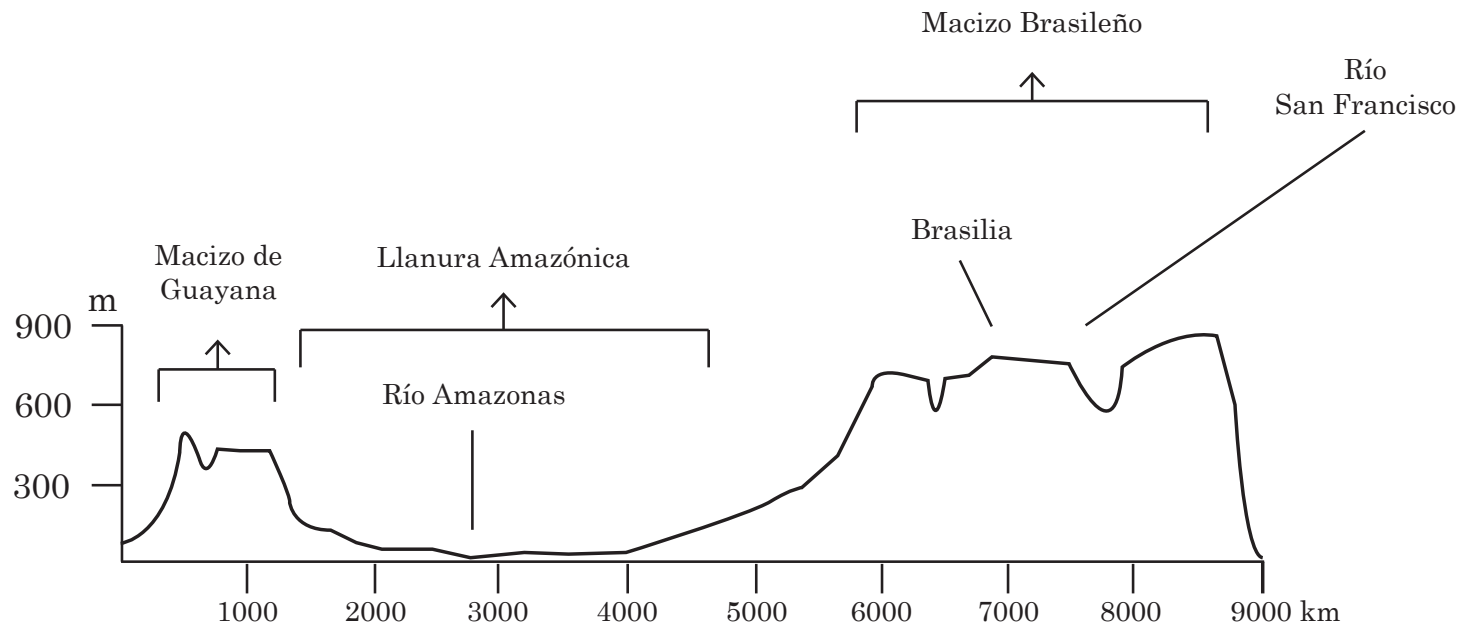

Fuente: Mapa de América del Leer. Escala 1:50, 000 000. Editorial Kapeluz, 2006. Buenos Aires. 
Figura 10

Densidad de población

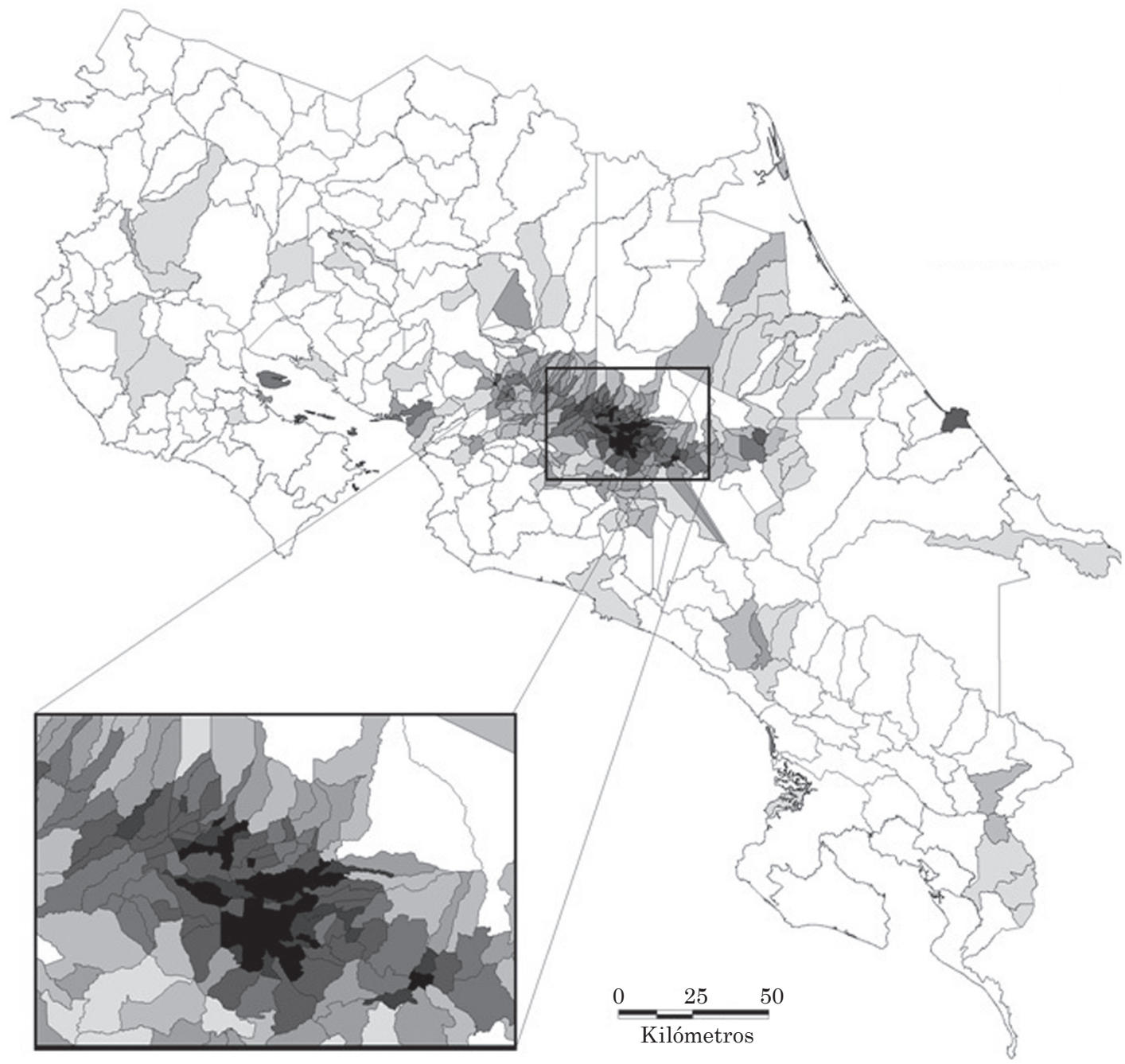

Densidad de población $\mathrm{N}^{\circ}$ de habitantes KM2

Menos de 50 habitantes 50 a 100 habitantes 100 a 250 habitantes 250 a 500 habitantes 500 a 1,000 habitantes 1,000 a 3,000 habitantes 3,000 a 5,000 habitantes Más de 5,000 habitantes 
Figura 11

África: mortalidad infantil

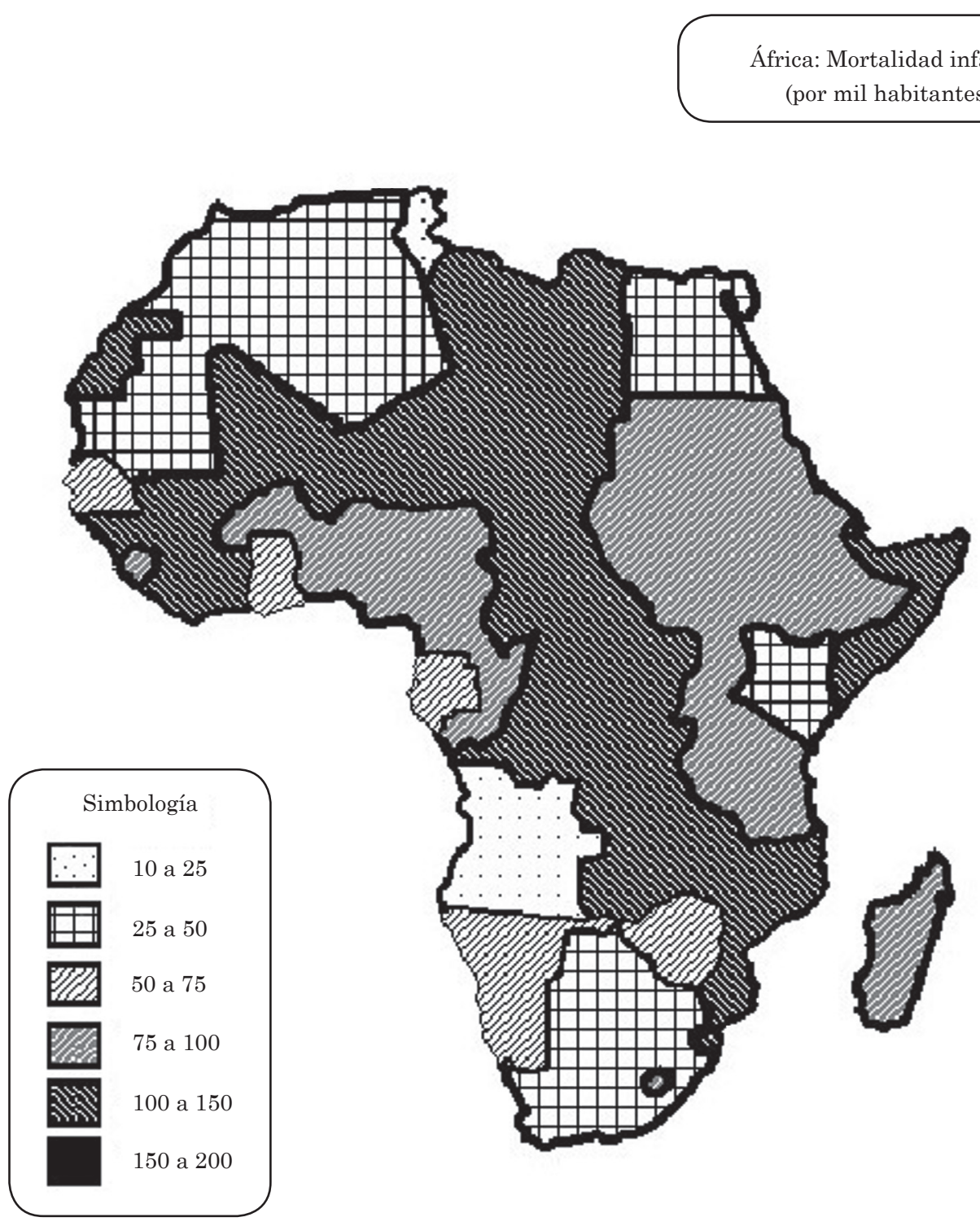

Fuente: Almanaque Mundial 2008. Estadística de Salud, pp. 560-565. Editorial Televisa, México. 
Esa situación se explica con las siguientes cuatro argumentaciones, derivadas de la investigación que se llevó a cabo con docentes de Estudios Sociales de secundaria, mencionada anteriormente:

1. En su formación académica universitaria, particularmente en las escuelas de Geografía, el profesor o profesora de Estudios Sociales recibió mayoritariamente cursos de Geografía Regional y no tuvo cursos de matemática elemental ni de Estadística; por esta razón presentan limitaciones en su formación académica para resolver problemas elementales, como la regla de tres y los análisis de porcentajes. Asimismo, desconocen a cuáles fuentes recurrir para obtener la información y la dificultad de esto aumenta debido al limitado conocimiento conceptual adquirido a lo largo de la formación profesional para el análisis y la interpretación geográfica de los datos.

2. Por la pobre formación en el área matemática y estadística, el profesorado de Estudios Sociales siente resquemor e indisposición por el uso de esas disciplinas, argumentado falta de tiempo para hacer las prácticas.

3. Las clases de Geografía, por lo general, son teóricas y no se construyen gráficos y si aparecen en libros de texto no se explotan como recurso didáctico, sino que se convierten en mera ilustración.

4. Existe una preocupación en el profesorado y presión de parte del Ministerio de Educación por cumplir los programas, en especial en aquellos niveles donde se aplican pruebas nacionales, lo que da poco espacio para la aplicación de prácticas basadas en la estadística (Cuadro 6).

Cuadro 6

Uso de la estadística como recurso didáctico por parte de los profesores de Estudios Sociales en colegios del Área Metropolitana

\begin{tabular}{|l|c|c|}
\hline Uso de la estadística & No & Si \\
\hline Utiliza fuentes primarias de datos para prácticas & $93,7 \%$ & $14,7 \%$ \\
\hline Elabora gráficos y los trabaja con los estudiantes & $85,3 \%$ & $58,6 \%$ \\
\hline Comenta con los estudiantes los gráficos de los libros de texto & $41,4 \%$ & $8,8 \%$ \\
\hline Realiza prácticas estadísticas con porcentajes con los estudiantes & $91,2 \%$ & $0 \%$ \\
\hline Realiza prácticas estadísticas de la mediana, moda y desviación & $100 \%$ & $2,2 \%$ \\
\hline Coordina con el profesor de matemática prácticas con estadísticas & $97,8 \%$ & \\
\hline
\end{tabular}

Fuente: Elaboración propia. Marzo 2008.

En Costa Rica existen instituciones públicas que producen datos estadísticos, entre ellas, el Instituto Meteorológico Nacional, que provee datos de lluvia, temperatura, humedad relativa. A partir de esas estadísticas se pueden elaborar análisis de régimen de lluvias, duración de estación seca, periodo lluvioso, meses de menor o mayor cantidad de lluvia; todo esto por medio de gráficos y cuadros (Figura 12). 
Figura 12

Régimen de lluvia

$\mathrm{mm}$.

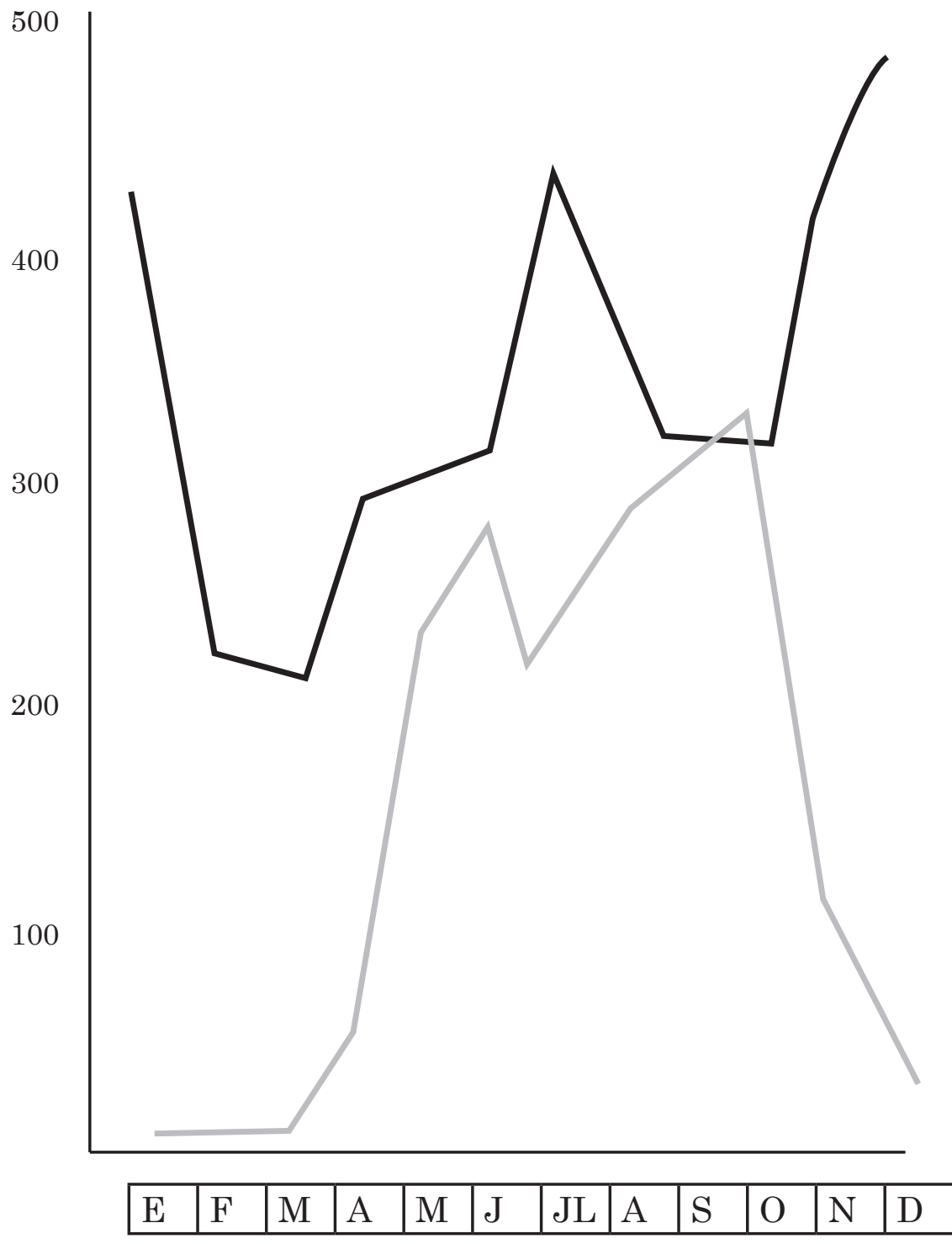

MESES

Vertiente Pacífica

Vertiente Caribe 
Cuando se presentan gráficos delluvia en los libros de texto estos son ilustrativos y quizá en unos pocos se plantean algunas preguntas muy sencillas y obvias como ¿En qué mes llueve más? o ¿En qué mes llueve menos? Pero no se pregunta el porqué de las causas que originan que estos meses sean los más lluviosos o los más secos. La Figura 12 es muy importante, porque con ella es posible dar toda una clase sobre el clima de Costa Rica. Se selecciona como ejemplos las situaciones que se presentan en el mes de julio y octubre.

En primer lugar las situaciones son opuestas, ya que en julio llueve en el lado Caribe mientras que en el Pacífico disminuye, situación que se invierte en octubre. Lo importante en estos casos es explotar al máximo los gráficos, por lo que se puede preguntar: ¿Cuál es el origen de esta situación? En el mes de julio llueve en el Caribe porque se da una incursión de los vientos alisios del Noreste que provocan lluvias en las llanuras y las vertientes de las montañas del sector Caribe, pero al pasar al Pacífico se produce una subsidencia de ellos y bajan secos al sector Pacífico; también influye que el viento alisio del suroeste pierde intensidad y que la zona de convergencia intertropical en este periodo del año se localiza al sur de Costa Rica. Esta situación se conoce con el nombre de veranillo de San Juan o Canícula. En el mes de octubre llueve mucho en el Pacífico porque los alisios del suroeste penetran con su mayor fuerza y arrastran la humedad del océano, al contrario, en el Caribe al perder los alisios del noreste fuerza se origina un descenso de las lluvias (Vargas, 2006).

El Instituto Nacional de Estadística y Censo (INEC) proporciona datos del número de habitantes, distribución de la población por sexo y edad, densidad de población por cantones, migración internacional e interprovincial y analfabetismo. La Figura 13 muestra la distribución por sexo y edad de la población para 1950 , 1984 y 2000 y una proyección para el año 2025. La pirámide de población del año 1950 muestra un dominio de la población joven, en especial los menores de 15 años, de ahí la base muy ancha que presenta la pirámide en los primeros cuatro niveles. Este dominio de la población joven se debe a una natalidad muy elevada y a un descenso de la mortalidad, que es la característica dominante en el periodo de 1950 a 1963.

La pirámide de la población de 1984 muestra el cambio hacia una población "relativamente madura" ya que domina la población entre los 15 y 35 años, esto se produjo por tres razones; primero, la disminución sostenida de la mortalidad a partir de la década de 1950; segundo, la disminución que empezó a experimentar la natalidad después de 1960 y tercero, el moderado ingreso de extranjeros al país.

Para el año 2000, Costa Rica deja definitivamente el perfil de población joven que la caracterizaba en 1950 y muestra un paulatino ritmo de envejecimiento de su población, en el que los menores de 10 reducen su número y se aumenta en edades mayores de 40, pero en especial de 65 años y más. Esta estructura es el resultado de una mortalidad baja y estable, una fecundidad en descenso y una inmigración internacional que se incremento durante las dos últimas décadas.

La población mayor de 60 años se va a incrementar y, según la proyección al 2025, se va a envejecer aún más, tal situación pone en evidencia la importancia que hay que prestarle a esta población y, en consecuencia, la necesidad de que se convierta en objeto para el diseño de estrategias de desarrollo y políticas especificas (Vargas, 2006).

El Banco Central de Costa Rica mantiene datos de exportación, producto interno bruto (PIB), ingreso de divisas según sectores de producción. El Instituto Costarricense de Electricidad tiene datos sobre caudales de ríos y lluvia; el Instituto Mixto de Ayuda Social de pobreza y tugurios y el Instituto Costarricense de Turismo genera datos sobre el ingreso de turistas y divisas. Otras estadísticas se encuentran en publicaciones como el Estado de la Nación o el Almanaque Mundial para temas de Geografía regional mundial. El Internet 


\section{Figura 13}

Distribución de la población por sexo y grupos quinquenales de edad. 1950, 1984, 2000 y 2025

1950

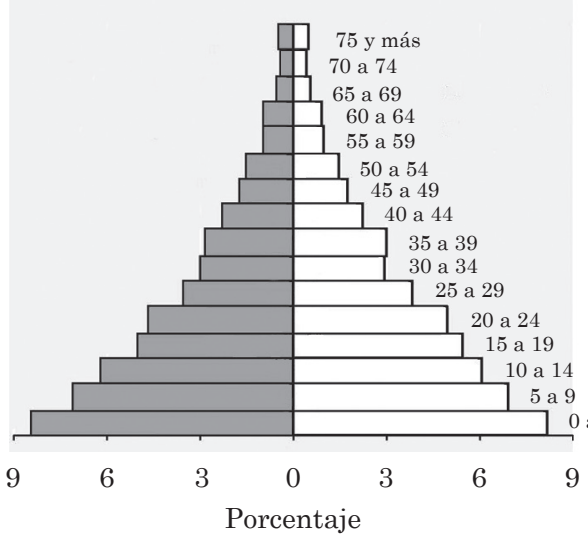

2000

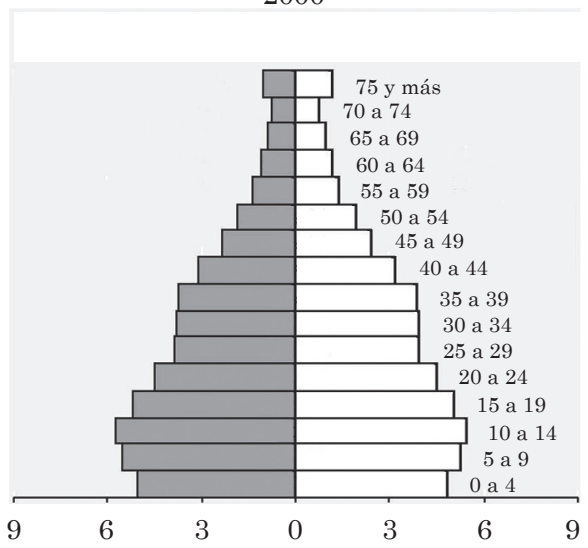

Porcentaje
1984

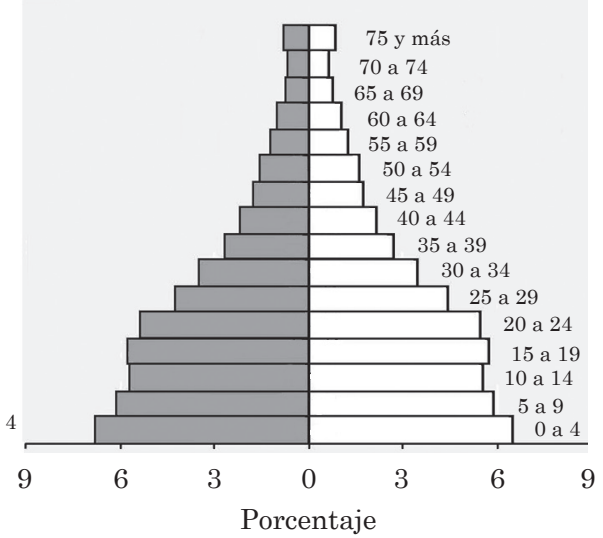

2025

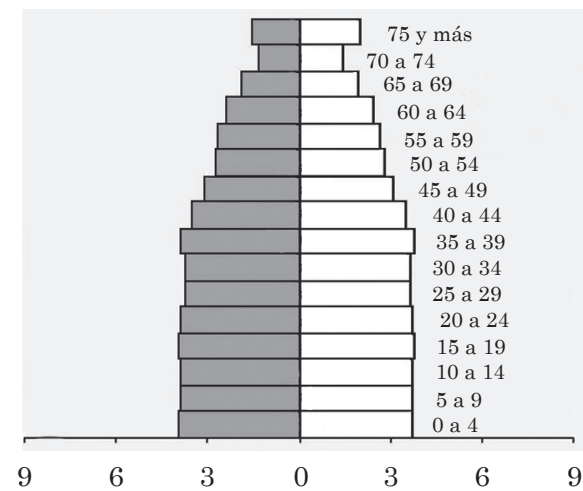

Porcentaje

Hombres

Mujeres

Fuente: $\quad$ Censo Nacional 1950, 1984 y 2000. Instituto Nacional de Estadística y Censos. Proyecciones y Estimaciones de Población, 1955-2025. Programa Centroamericano de Población, Universidad de Costa Rica, Área de Estadística y Censos, MEIC, 1998. 
permite obtener datos actualizados de organización como la UNESCO, Banco Mundial, Organización Mundial de la Salud, entre otros.

Los libros de texto para colegios, utilizados en países de una gran tradición geográfica como los Estados Unidos (Withman, Miyares y Schug, 2007) y Francia (Bouvet y Lambin, 2004; Pitte y Claval, 2001) utilizan la estadística por medio de gráficos, tablas como apoyo a los contenidos y con ellas se desarrollan igualmente prácticas para los estudiantes. Souto (1996) recomienda para los liceos de España que las prácticas de Geografía deben incluir el análisis estadístico por medio de la moda, mediana y desviación típica, uso de bases de datos y programas estadísticos y graficaciones. Esta sugerencia de Souto para la enseñanza de la Geografía, no se cumplen en Costa Rica por las razones ya antes expuestas y debido al limitado apoyo informático en los colegios públicos, aunque esto último no es indispensable para realizar prácticas sencillas.

\subsection{Las fuentes literarias en la didáctica de la geografía}

Las fuentes literarias son un enriquecimiento y una complementariedad en el desarrollo de temas geográficos. El trabajo del geógrafo y literato que describe el espacio es complementario: existen similitudes en la labor de uno y otro; pues ambos tratan de explicar las respuestas del individuo o de la sociedad a un medio determinado, ambos son conscientes de la existencia de un espacio y un lugar, además, el hecho de que cada uno de ellos resalta una experiencia o una faceta del espacio, sea este un paisaje, una región, una ciudad o el medio rural, no es obstáculo para que analizados conjuntamente, restituyan una visión más rica y completa de ese medio estudiado (Boira y Regues, 1996).

Al enseñar Geografía por medio de fuentes literarias el principal interés está en sus contenidos, ya que se convierten en un recurso didáctico para explicar conceptos y preparar al estudiante para una explicación de un determinado fenómeno o concepto geográfico. Al tomar una novela como referencia, el geógrafo puede explicar de ella elementos corológicos que hacen referencia a lugares o regiones como un desierto, un bosque o bien determinar algunas características y expresiones ligadas a costumbres o a fenómenos como las condiciones climáticas.

La documentación histórica geográfica de viajeros naturalistas es útil para reconstruir un paisaje o conocer las tradiciones y costumbres de un pasado, en este caso la Geografía histórica permite la reconstrucción de ese pasado. A continuación tomaremos algunas fuentes literarias como ejemplos de recursos didácticos en la enseñanza de la Geografía.

Para explicar el objeto de la geografía y el trabajo que hace el geógrafo vamos a tomar un texto de la obra El Principito de Antoine de Saint Exupéry (2004).

—¿Qué es ese libro tan grueso? — dijo el Principito. ¿Qué hace aquí?

—-Soy geógrafo — dijo el anciano.

- ¿Qué es un geógrafo?

- Es un sabio que sabe donde se encuentran los mares, los ríos, las ciudades, las montañas y los desiertos.

—Esto si es interesante -dijo el Principito. ¡Esto si que es un verdadero oficio!

- Su planeta es muy hermoso. ¿Tiene océanos?

- No puedo saberlo - dijo el geógrafo

— iAh! —el Principito estaba decepcionado, — ¿y montañas?

- No puedo saberlo - dijo el geógrafo.

— ¿Y ciudades y ríos y desiertos?

- Tampoco puedo saberlo - dijo el geógrafo.

— ¡Pero si usted es geógrafo!

- Exacto - dijo el geógrafo- pero no soy explorador. El geógrafo no tiene porque llevar la cuenta de las ciudades, de los ríos, de las montañas, de los mares, de los océanos y de los desiertos. El geógrafo es demasiado importante para andar ambulante. No deja su despacho. Pero en él recibe a los exploradores, los interroga y toma nota de sus observaciones. Y si las observaciones de alguno de ellos le parecen interesantes, el geógrafo manda hacer una inspección acerca de la moralidad del explorador.

- ¿Y eso porqué?

- Porque un explorador que mintiera produciría catástrofes en los libros y mapas de geografía y luego cuando la moralidad del explorador parece buena, se hace una investigación acerca de su descubrimiento (pp. 63-64). 
Del texto anterior se pueden explotar tres ideas. La primera es la Geografía como una ciencia de síntesis, esta idea se observa cuando el geógrafo recibe a los exploradores que le informan de sus recorridos. Muy ligado a esto, está la segunda idea: el objeto de la Geografía. Ella es una ciencia que tiene muchos objetos; de esta manera los objetos de estudio se los proveen los exploradores. Ellos representan las diversas ciencias como la Botánica, la Geología, la Demografía, la Economía de las cuales el geógrafo toma su objeto de estudio. La tercera idea es el método de la Geografía que se observa cuando el geógrafo somete a la duda el conocimiento de los exploradores, lo comprueba en campo para finalmente representarlo en mapas.

Para temas de contaminación y marginalidad destacan la obra Marcos Ramírez de Carlos Luis Fallas y Única mirando al mar de Fernando Contreras.

Para desarrollar y comentar estos temas, el profesor debe ubicar las obras en el contexto espacial y temporal; en este caso el barrio del Llano en Alajuela y Río Azul en San José, en especial demostrando los cambios que se producen en la actualidad.

"Momboñombo aún prefería quedarse en casa en labores domésticas antes de ir a buscar; se pasaba las horas tratando de idear un sistema de ventilación del tugurio, de modo que entrara el viento que venía del lado contrario al basurero, haciendo pasar por una suerte de embudo de cartones que instalo en el techo en medio de una barrera protectora de cartones también, cuya función consistía en repeler la ventisca caliente que mezclaba el hedor fétido de la basura con el humo del combustible de los tractores" (Contreras, 1994, p. 31).

"Más o menos veinte años de estar enterrando basura había hecho de la geografía de la colina un esperpento cuya representación cartográfica resultaría algo así como el contorno del lomo de un monstruo de pesadilla, montículos y montículos por todos lados y tierra removida de aquí para allá, y los ríos Damas y Tiribí condenados a beberse los caldos que se infiltran constantemente; pero solo una parte de ellos, porque el resto iba a dar a los mantos acuíferos profundos, inyectándose de manera intravenosa en el cuerpo de la tierra" (Contreras, 1994, p. 49).
"Lengua azul nos propuso que nos fuéramos a bañar a la llamada plaza del Brasil... Cuando llegamos al río yo me quedé embobado y maravillado por aquel extraordinario espectáculo que por primera vez contemplaban mis asombrados ojos. Ya casi desemboca al río Ciruelas, el torrente del Brasil se precipitaba desde un alto y al caer se resolvía en turbiones violentas y espumosas, y después sus aguas se cercenaban y entendían en un amplio remanso, casi circular, rodeado de altos y rocosos paredones y sombreado todo por el fresco y cenado ramaje de un enorme sotocaballo. Y del remanso surgía, más fuerte aún que el cuerdo rumor de las aguas, una alegre algarabía de grutas y de risas, y bullían por todas partes las muchachas desnudas con sus calabazas amarradas a la cintura para poder flotar" (Fallas, 1997, p. 57).

El crecimiento urbano es posible analizarlo en fuentes literarias, dos ejemplos los tomamos de Marcos Ramírez de Carlos Luis Fallas, que ya hemos citado y de la obra de Gaetano Pandolfo Rímolo, Para nunca olvidar.
Y es que vivía más en el campo en las afueras del barrio de La Concepción, o del Llano, muy lejos de la ciudad, y nuestros vecinos más cercanos no lo estaban mucho" (Fallas, 1997, p. 31).

"Me crié en el barrio La Dolorosa..., es un lugar muy céntrico y a las 'güilas' del barrio todo nos quedaba cerca; iglesias, cines, plazas, farmacias y también escuelas y colegio. Estudio en la escuela Juan Rudína tres cuadras de mi residencia" (Pandolfo, 1997, p. 5).

Para estudiar los temas de localización por coordenadas geográficas destaca por sus riqueza y variedad de ejemplos la obra de Julio Verne Los hijos del capitán Grant, que se puede trabajar con el apoyo de un mapamundi para la ubicación de los lugares. (Ver ejemplo en recuadro de la siguiente página). 
"Lord Glenervan tomó la pluma y redactó la siguiente nota: El 7 de junio de 1862 la fragata Britannia de Glasgow zozobró en las costas de la Patagonia en el hemisferio austral. Dirigiéndose a tierra firme, dos marineros y el capitán Grant van a intentar abordar el continente donde serán prisioneros de las crueles indias. Han arrojado este documento a los grados de longitud $31^{\circ} 15^{\prime \prime}$ y $37^{\circ} 11^{\prime \prime}$ de latitud. Socorredles o están perdidos" (Verne, 1994, p. 306).

"La pampa argentina se extiende desde $34^{\circ}$ al $40^{\circ}$ de latitud austral. La palabra pampa se aplica muy justamente a esta región, porque es una palabra de origen araucano, que significa llanuras de yerbas. Le dan un singular aspecto las mimosas arborescentes de su parte occidental y las sustanciales yerbas de su parte oriental. Esta vegetación está arraigada en una capa de tierra de aluvión que cubre la arenosa aralla, amarilla o roja... Si el geógrafo inspeccionase esta tenemos de época terciaria y encontraría riqueza abundante. Allí nacen infinidad de osamentas centidiluviones que atribuyen las indias a extinguidas razas de grandes armadillos, quedando sepultados bajo aquel polvo de historia primitiva" (Verne, 1994, pp. 363-364).

\subsection{Los periódicos y revistas en la didáctica de la geografía}

La prensa ofrece una gran información muy fácil de obtener en periódicos o revistas. Las noticias suceden todos los días en un espacio que puede variar desde un país al mundo entero, esto permite en primer lugar realizar un análisis de localización y distribución de las noticias a diferentes escalas.

En un mapa del mundo o del país se pueden localizar las noticias y solicitar información complementaria del país del cual procede como características de la población, datos socioeconómicos, capital u otros para tener un mayor conocimiento. En segundo lugar, las noticias de terremotos, inundaciones, sequías, hambrunas, incendios forestales, etc. tienen efectos en el espacio geográfico o territorio y en las sociedades. Un aspecto muy importante por tomar en cuenta en el momento de solicitar noticias a los estudiantes es definir muy bien la temática a estudiar y evitar que los estudiantes proporcionen noticias deportivas y de espectáculos.

Las noticias vienen acompañadas con croquis, dibujos, fotos, mapas, estadísticas que sirven para aclarar conceptos; por ejemplo siempre que hay un terremoto o temblor; se ilustra con croquis del movimiento de placas, de fallas o del epicentro que hace más comprensible los conceptos y procesos (Ver Figura 14).

\subsection{El tiempo en los estudios geográficos}

Todo proceso o fenómeno geográfico ocurre en un espacio o escala espacial y en un tiempo determinado o escala temporal, en ambos casos es necesario conocer el concepto de distancia. La escala espacial está relacionada con el espacio físico, mientras que la temporal se relaciona con la percepción del tiempo.

Cuando nos encontramos en una situación de preocupación o angustia el tiempo se nos hace muy largo, la percepción del tiempo cambia, se dilata y un minuto puede parecer un espacio de tiempo muy largo. Por el contrario, al enfrentarnos a una situación placentera, nuestra percepción del tiempo se acorta. Las personas tienen la capacidad de imaginar tiempos con una magnitud que guarde una relación razonable con la duración de su vida. De esta manera, para el ser humano los segundos, minutos, horas, meses, años o incluso siglos son comprensibles. Pero, si se habla de treinta mil años, se dirá que es mucho tiempo y si se habla de cien mil o un millón de años se diría que es muchísimo tiempo. A la imaginación de las personas le da lo mismo doscientos mil que trescientos millones de años.

En todo estudio geográfico se debe integrar el tiempo a sus razonamientos. Una de las dificultades en el análisis geográfico, es que el geógrafo tiene que enfrentarse a dos diferentes escalas temporales: la escala geológica de cientos y millones de años y la escala humana de una centena de años. 
Figura 14

La noticia como recurso didáctico

- Terremoto del sábado ocurrió a una profundidad de 5 a 10 kilómetros

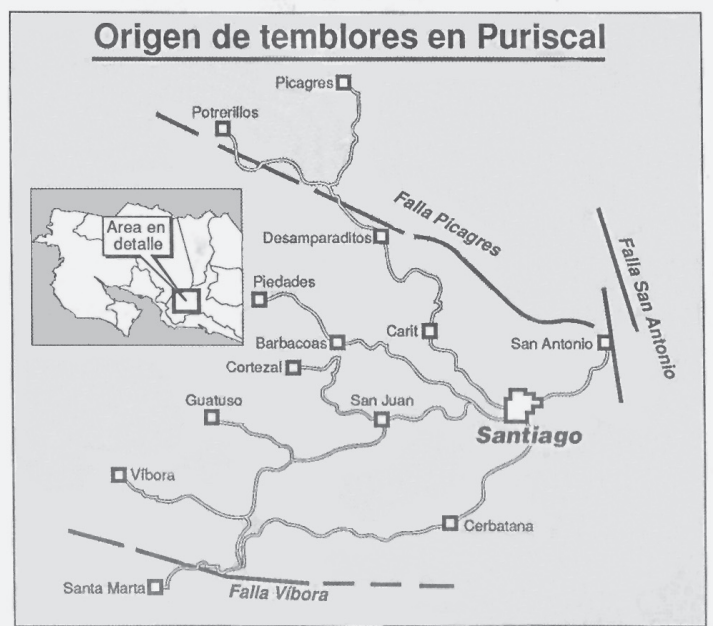

do) está localizado a unos 15 kilómetros de Alajuela, que es una distancia muy corta; luego siguen Heredia y San José, y ese es el mismo
comportamiento de los daños. "La otra cuestión que observamos es que en el barrio El Carmen hay danos muy concentrados en casas construidas en diferente tiempo y por personas distintas. Pensamos que has un dad; es decir, la intensidad del sismo en Alajuela es VII en la escala Mercalli, pero posiblemente en el barrio El Carmen es ligeramente superior o sea de hasta VIII, y uno de los posibar amplificar el movimiento. Esa es una probable explicación, ya que apenas estamos recopilando - ¿Por qué un sismo de baja intensidad como el del sábado provoca tantos destrozos en comparación con otros de mayor intensidad? a 10 kilóm fuperficial, dor a cual la enería se despre promuy cerca de la superficie del terreno. Muy poco trayecto para amortiguarse esa energi. además de que habia centros de población rel

\section{Créditos}

Elaboraron estas informaciones los periodistas Carlos Arguedas, Nelson Murillo, María Isabe Armando Mayorga. Las fotografías son Frank Guevara, José A. Venegas, Ronald Cha

El terremoto de Cóbano, que se produjo el 25 causante de toda la ola sismica ocurrida durane este anio, decla de ay srense. Walter Montero, subdirector de la Escuela de Geología de la Agrego que el mencionado temblor no sólo ayudó a activar tres fallas en Puriscal sino que también hizo que otras rupturas en el territorio aca证

Montero hizo ver, en una amplia entrevista, que el terremoto de Picagres, ocurrido el sábado las y 10 kilómetros.

Asimismo, mencionó que el hecho de que en el barrio El Carmen de Alajuela se produjeran tantos danos es atribuible a que el suelo, posiblemente por algun defecto

Lo siguiente es un extracto de la entrevista Éte año estuvo marcado por el terremot
Estemono de Cóbano, ocurrido el 25 de marzo y que tuvo de este sismo se empezó a dar una el interior del país, como los temblores ocumidos en la región del volcán Poás, también los presentados cerca del Zurquí, otros al sur la del territorio están relacionadas eon el sisento Cobano, ya que éste sobrecargo fuerzas esas fallas situadas alrededor del Valle Central.

"También hay que mencionar que hubo actividad en el borac Po de 5 a 6 grados y otro fuerte en la región de Peninsula de Santa Elena (Guanacaste, que fie que se sintió cuales suponemos tienen alpun Nicaragua, los de Cóbano".
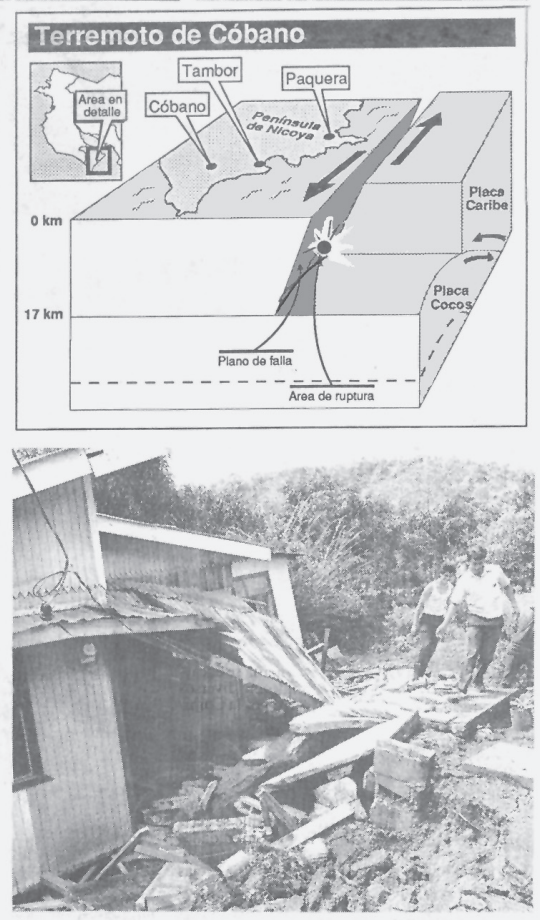

Factores especiales, como el terreno, aumentaron la intensidad del sismo y,
por ende, el nivel de destrucción.

Fuente: Periódico La Nación, Sección Nacionales, del martes 25 de diciembre de 1990, p. 4A. 
El geógrafo utiliza en sus estudios tres escalas de duración: el ciclo, la duración histórica y la duración geológica. El ciclo es la repetición en un tiempo rítmico que permite establecer una frecuencia, por ejemplo, la agricultura itinerante que practica el campesino en el frente pionero, donde cada año se repite el ciclo tala del bosque, quema, siembra y barbecho; otro ejemplo es la temporada de huracanes en el mar Caribe. La duración histórica que abarca decenas y centenas de años se estudia por medio de documentos y se debe integrar al espacio geográfico.

El geógrafo observa lo que ocurre en el presente y únicamente recurre al pasado con vistas a la comprensión del paisaje, para entender la evolución. No obstante, en la actualidad existe una corriente geográfica que pretende conocer cómo era el paisaje y su evolución en el pasado histórico, por lo tanto, trata de encontrar en el paisaje las huellas del pasado (Bertrand, 1975; Fines, 1968; Lacoste, 1977; Pitte, 1983). En la duración geológica se abarcan millones de años y se recurre a fósiles, sedimentos y roca para sus estudio, a los cuales se les establece la edad aproximada por medio de dataciones o por medio del estudio de formas de relieve sometidas a procesos de erosión y desnudan el pasado, al mostrar su paisaje, por ejemplo el Gran Cañón del río Colorado y los efectos de las glaciaciones en el cerro Chirripó.

Una de las características de los movimientos de la naturaleza es que no se producen de forma paulatina sino repentina. Si los movimientos son masivos pueden llegar a ser catastróficos. Por ejemplo: una ladera es inestable hasta que llega a un punto de ruptura y se desliza. Pero para que alcance ese punto de ruptura ha tenido que acumular una cierta tensión a lo largo del tiempo. Los períodos de inactividad son más largos que los de actividad. Claro que esto sólo es verdad si utilizamos una escala de tiempo humana. Si hablamos de tiempos geológicos que una ladera se desplace cien metros en media hora supone un movimiento mínimo, y la erosión de una montaña puede considerarse paulatina.

Para comprender los procesos y fenómenos que ocurrieron hace millones de años, lo conveniente es relacionarlos con la escala humana o al tiempo que se maneja regularmente como puede ser el calendario anual. La Figura 15 representa y restringe la formación y evolución geológica de Costa Rica a un año para una mejor comprensión. Se puede plantear que el inicio de la formación geológica de Costa Rica ocurrió hace aproximadamente 210 millones de años, cantidad de tiempo que no es posible percibir con exactitud. Pero al reducir estos 210 millones de años un año es más fácil entender el proceso de formación.

Se puede observar (ver Figura 15) que el primero de enero que corresponde a hace 210 millones de años lo que existía en el espacio que hoy ocupa el territorio continental de Costa Rica era un canal interoceánico que comunicaba al océano Pacífico y al Atlántico. Pasaron enero, febrero, marzo, abril, mayo, junio, julio y no había signos de formación de tierras continentales. Fue hasta el 31 de agosto, ocho meses más tarde que aparece un arco de islas en el sector Pacífico que se formaron por un vulcanismo submarino, pero siempre con el dominio del canal interoceánico. Mes a mes se fue formando nuestro territorio al aparecer nuevas tierras. El 22 de setiembre se formaron las serranías de Nicoya y Osa, el 20 de octubre la cordillera Costeña, el 26 de noviembre apareció la primera cordillera volcánica de Costa Rica, la cordillera de Tilarán y los montes del Aguacate, el 3 de diciembre se dio el levantamiento de Talamanca, el 26 de diciembre se formaron la cordillera volcánica de Guanacaste y la Central, con lo que se interrumpe el canal interoceánico. El 30 de diciembre aparecieron las llanuras y de manera se formó es el actual territorio de Costa Rica. Es importante, resaltar que un minuto antes de finalizar el año aparecieron los seres humanos y 15 segundos antes del año nuevo se formo el volcán Arenal. 


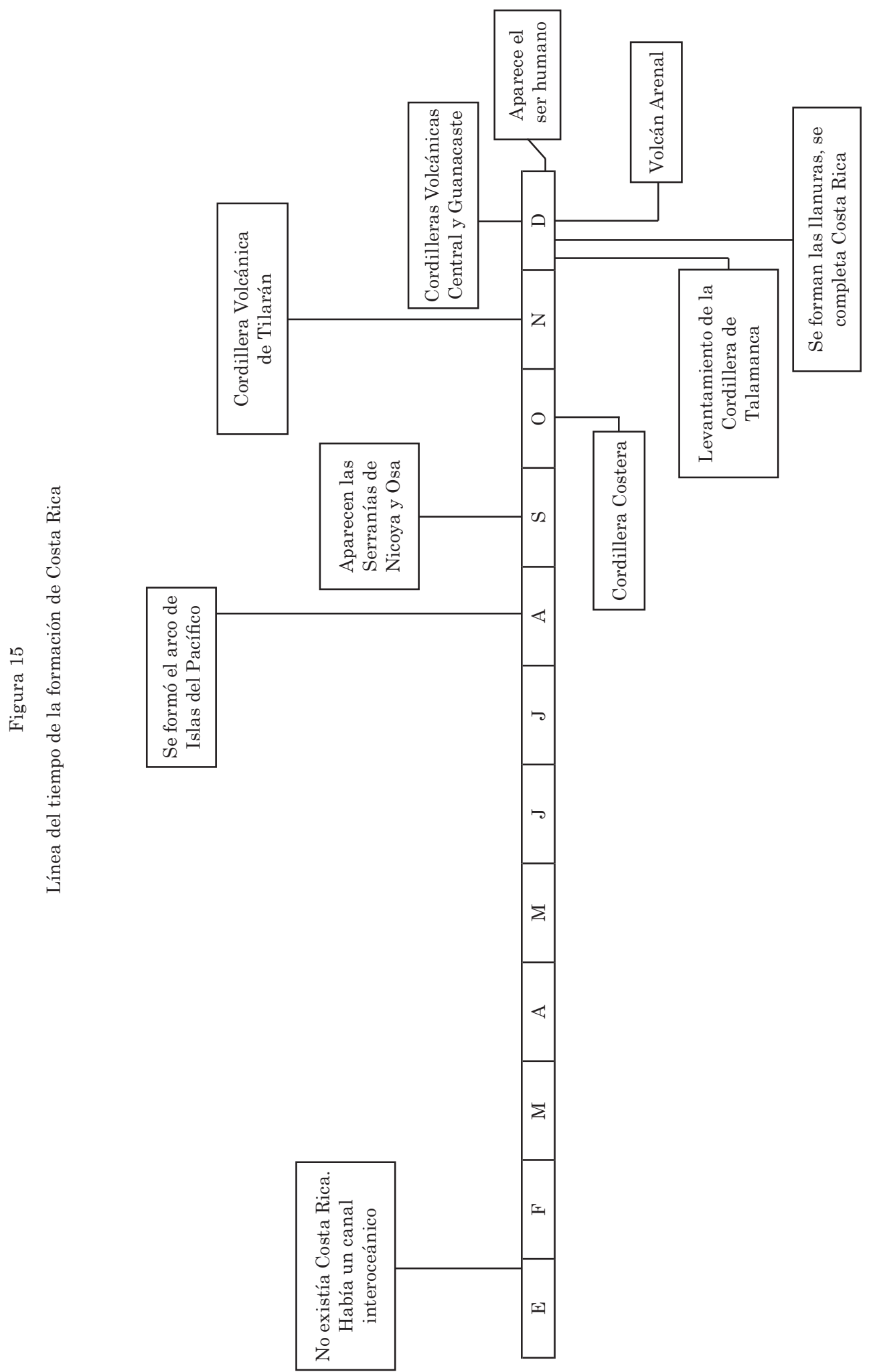


Otro caso difícil de comprender, es cuando se desarrolla la formación de Costa Rica y se comunica al estudiante que Costa Rica es un país joven, pues comenzó su formación hace 70 millones de años. Al hablar de joven y mencionar tal cantidad de millones de años se hace difícil la comprensión. Pero si se ilustra con el siguiente ejemplo y se dice que el continente africano que se formó hace 650 millones de años es una abuelita de 90 años y Costa Rica que se formó hace 70 millones de años es una niña de 8 años. Nuevamente, al relacionarlo con la escala humana, la idea es más clara y comprensible y es muy fácil de obtener por medio de una sencilla regla de tres.

\section{Conclusión}

La Geografía se encuentra, actualmente, llamada a responder a una demanda con profundas connotaciones sociales: globalización, cambio climático, desarrollo humano, diversidad biológica, social, económica y cultural, y desarrollo sustentable; todo lo cual implica no sólo la individualización de interrelaciones, sino también el posicionamiento en una dimensión ética y solidaria con las nuevas generaciones.

La necesidad de estudiar en profundidad los cambios ocurridos en el medio ambiente a partir de los procesos de desarrollo económico ha llevado a la Geografía a enriquecer el enfoque geográfico y las temáticas de estudio. La Geografía se ha preocupado cada vez más de la relación entre el ser humano y la naturaleza y ha visto enriquecido su campo de estudio por efecto de esta nueva conciencia ambiental que predomina hoy en el mundo.

El interés por el medio ambiente y el desarrollo constituye un proceso que está transformando el estudio del territorio hacia un enfoque más integral y sistémico. No basta con estudiar cada uno de los distintos objetos que conforman el paisaje, sino que resulta importante estudiar las interconexiones o interrelaciones que sur- gen entre los distintos elementos de un sistema espacial. Es necesario estudiar el impacto de la acción humana en el aumento de los desastres, en la preservación de la naturaleza, en la conservación de las condiciones que las nuevas generaciones demandan a la actual, para lo cual la geografía tiene un rol fundamental que cumplir.

La enseñanza de la geografía en los colegios de nuestro país se encuentra en una situación muy difícil, diríamos deficiente y limitada, en especial por dos razones. La primera tiene que ver con una formación geográfica limitada, parcial y tradicional y segundo se presenta una ausencia de reflexión didáctica sobre la disciplina

La enseñanza de la geografía no tiene por meta la formación de jóvenes geógrafos, sino más bien pretende que el estudiante utilice el conocimiento geográfico para su educación, sin que sea necesario un conocimiento exhaustivo de la geografía. Es suficiente que los estudiantes a la salida del colegio tengan una curiosidad sobre los problemas de la geomorfología, climatología, de la biogeografía, y de aspectos espaciales de la geografía humana.

Los estudiantes deben adquirir nociones y habilidades que se interrelacionan entre sí, pero para ello es necesario estructurar el aprendizaje, de manera que la enseñanza se realice en una forma gradual.

En el plano educativo, la didáctica de la Geografía pretende, proporcionar sólidos conocimientos y explicar la organización del espacio o sus equivalentes conceptuales: superficie terrestre, territorio, paisaje y lugar desde la interrelación de los sistemas físicoambientales, económico-sociales, culturales y desde la definición de sus estructuras, que permitan comprender e insertarse en la dinámica de los cambios que los adelantos de la ciencia, la tecnología y la globalización exigen en las distintas escalas territoriales. La educación geográfica busca fomentar el arraigo y la construcción de pertenencia con los lugares y destacar la importancia del uso de los lenguajes de la Geografía en el marco de las Ciencia Sociales. 


\section{Referencias bibliográficas}

Audigier, P. (1977). Problèmes, problèmatiques et perpectives de la didactique de la geographie [Problemas, problemáticas y perpectivas de la didáctica de la geografía]. Bulletin de $l^{\prime}$ Association de Geographes Français, 74(3), 226-235.

Bale, J., Graves, N. y Walford, R. (1985). Perpectives in geographical education [Perspectivas en la educación geográfica]. Edimburgo: Oliver and Boyd Editions.

Bertrand, G. (1968). Paysage et géographie physique globale: Esquisse méthodologique [Paisaje y geografía física global: Esbozo metodológico]. Revue de Géographie et du Pyrénées et du Sud-Ouest, 39(2), 249-272.

Bertrand, G. (1975). Pour une histoire écologique de la France rurale. Tome 1 [Por una historia ecológica de Francia rural. Tomo 1]. Paris: Editions Sevil.

Bertrand, G. (1978). Le géosysteme ou "sistéme territorial naturel" [El geosistema o "sistema territorial natural"]. Revue de Géographie et du Pyrénées et du Sud-Ouest, 49(2), 32-56.

Bertrand, G. y Dollfus, G. (1973). Le paysage et son concept [El paisaje y su concepto]. L' Espace geographique, 2(3), 161-163.

Boardman, D. (1986). Graphicacy and geography teaching [Gráficos y enseñanza de la geografía]. En T. Bennets, Structure and progression in Geography [Estructura y progresión en geografia] (pp. 169-173). Londres: Croom Helm.

Boira, J. V. y Regues, P. (1996). Las fuentes literarias y documentales en geogra- fía. En A. Moreno y M. J. Marrón (Eds.), Enseña geografía: De la teoría a la práctica (pp. 277-295). Madrid: Editorial Síntesis.

Bouvet, C. y Lambin, J. M. (2004). Geographie 4eme [Geografía de cuarto año]. Paris: Hachette éducation.

Brunet, R. (1989). L'aveuglanté unité de la geographie [La deslumbrante unidad de la geografía]. L'Espace Geographique, 18(2), 25-37.

Buffet, F. (1986). Obstacles épistémologiques et travail scientifique en didactique de la geographie [Obstáculos epistemológicos en la didáctica de la geografía]. Revue de geographie de Lyon, 61(2), 164-177.

Castner, H. W. (1990). Seeking new horizons: A perceptual approach to geographic education [Buscando nuevos horizontes. Una aproximación perceptiva de la educación geográfica]. Montreal: Queen's University Press.

Claval, P. (1986). L'esprit de la geographie: Approche historique et logique [El espíritu de la geografía: Aproximación histórica y lógica]. Revue de Geographie de Lyon, 61(2), 159-165.

Comes, P. (1993). Los procedimientos en geografía. Revista Aula de Innovación Educativa, $\mathrm{N}^{\circ}$ 10, 28-33.

Contreras, F. (1994). Única mirando al mar. San José: Ediciones FARBEN.

Daudel, C. (1986). La recherche en didactique de la géographie [La investigación en didáctica de la geografía]. Revue de Géographie de Lyon, 61(2), 133-157.

Desplanques, P. (1991). La didactique de la géographie [La didáctica 
de la geografía]. $L^{\prime}$ Information Géographique, 55(3), 45-49.

Fallas, C. L. (1997). Marcos Ramírez. San José: Editorial Costa Rica.

Fines, K. O. (1968). Landscape evolution: Research project in Eastern Sussex. [Evolución del paisaje. Proyecto de investigación en Sussex del Este]. Regional Studies, $\mathrm{N}^{\circ} 2$, 41-55.

Flores, E. (1973). Geografía de Costa Rica. San José: EUNED.

Graves, N. J. (1984). Geography in education [Educación y geografía]. Londres: Heineman Educational books.

Graves, N. J. (1993). New movements in the study and teaching of geography [Nuevas tendencias en el estudio $y$ enseñanza de la geografía]. Londres: Maurice Temple Smith Editions.

Hall, C. (1984). Costa Rica: Una interpretación geográfica con perspectiva histórica. San José: Editorial Costa Rica.

Henriet, J. M. (1977). Les tendences nouvelles dans l'enseignement de la géographie [Las nuevas tendencias en la enseñanza de la geografía]. $L^{\prime}$ Espace Geographique, 6(4), 268-274.

Lacoste, Y. (1977). ¿A quoi sert le paysage? ¿Qu'est ce qu'un beau paysage? [¿Para qué sirve la geografía? ¿Qué es un bello paisaje?]. Herodote, $\mathrm{N}^{\mathrm{o}}$ 7, 3-4.

Lacoste, Y. (1996). Penser et enseigner la geographie [Pensar y enseñar geografía]. L'Espace Geographique, 25(1), 24-27.

León, J. (1942). Nueva geografía de Costa Rica. San José: Librería La Española.
Le Roux, A. (2003). Didactique de la géographie [Didáctica de la geografía]. Caen, Francia: Presses Universitaire de Caen.

Monge, C. (1943). Geografía social y humana de Costa Rica. San José: Imprenta y Librería Universal.

Moreno, A. y Marrón, M. J. (2000). Enseñar geografía: De la teoría a la práctica. Madrid: Editorial Síntesis.

Naish, M. (1989). Desarrollo mental y aprendizaje de la geografía. En N. J. Graves, Nuevo método en la enseñanza de la geografía (pp. 23-61). Madrid: Teide.

Obregón, M. (1932). Geografía general de Costa Rica. San José: Imprenta Lines y Reyes.

Osejo, R. F. (1833). Lecciones de geografía en forma de catecismo. San José: Imprenta La Merced de Velarde.

Pandolfo, G. (1997). Para nunca olvidar. San José: Imprenta y Litografía Gossestra Internacional.

Piaget, J. (1978). Psicología y pedagogía. Barcelona: Editorial Ariel.

Pinchemel, P. (1997). La geographie et l'enseignement [La geografía y su enseñanza]. Bull. Assoc. Geogr. Franc., N ${ }^{\circ} 3,224-2226$.

Pitte, J. R. (1983). Histoire du paisaje francaise [Historia del paisaje francés]. París: Editions Taillandier.

Pitte, J. R. y Claval, P. (2001). Geographie 2 ieme [Geografía de segundo año]. París: Editions Nathan.

Polanco, M. E. (1976). Didáctica de los estudios sociales. Universidad de 
Costa Rica, San José: Oficina de Publicaciones.

Quirós, T. (1944). Geografía de Costa Rica. San José: Instituto Geográfico Nacional, Ministerio de Obras Públicas y Transporte.

Rhys, W. (1972). The development of logical thinking [El desarrollo del pensamiento lógico]. En N. J. Graves, New movements in the study and teaching of geography [Nuevos tendencias en el estudio $y$ enseñanza de la geografía] (pp. 87-104). Londres: Maurice Smith Editions.

Rougerie, G. (1986). Geographie des paysages [Geografía del paisaje]. París: Presses Universitaire de France.

Rougerie, G. y Beroutchachvili, N. (1991). Géosystemes et paysages [Geosistemas y paisajes]. París: Armand Colin editions.

Saint Exupéry, A. (2004). El principito. San José: Editorial Lehmann.

Souto, X. M. (1996). Didáctica de la geografia: Problemas sociales y conocimiento del medio. Madrid : Editorial del Lesbal.

Tricart, J. y Killian, J. (1985). L'ecogeographie et l'amenagement $d u$ milieu natural [La ecogeografía y el ordenamiento del medio natural]. París: Francois Maspero.

Vargas, G. (2006). Geografía de Costa Rica. San José: Editorial de la Universidad Estatal a Distancia (EUNED).

Vargas, G. (2007). La relación sociedadambiente: De Humboldt y Marx a la geografía del paisaje. En J. P. Bergoeing y L. G. Brenes (Eds.), Práctica de la geografía (pp. 229. 238). Cartago: Editorial Tecnológica de Costa Rica.

Verne, J. (1994). Los hijos del capitán Grant. En R. H. Valle, Obras completas de Julio Verne. Tomo 6 (pp. 243 267). México: Editorial del Valle.

Walford, R. (1978). New directions in geographical teaching [Nuevas tendencias en la enseñanza de la geografía]. Londres: Longman Editions.

Walford, R. (1979). Games in geography [Juegos en la geografía]. Londres: Longman Editions.

Withman, S. W., Miyares, I. M. y Schug, M. C. (2007). World cultures and geography [Culturas del mundo $y$ geografia]. Dallas: McDougal Littell. 